SERVIÇO DE PÓS-GRADUAÇÃO DO ICMC-USP

Data de Depósito:

Assinatura:

\title{
Um Algoritmo Evolutivo para Aprendizado On-line em Jogos Eletrônicos
}

\author{
Marcio Kassouf Crocomo
}

Orientador: Prof. Dr. Eduardo do Valle Simões

Dissertação apresentada ao Instituto de Ciências Matemáticas e de Computação - ICMC-USP, como parte dos requisitos para obtenção do título de Mestre em Ciências - Ciências de Computação e Matemática Computacional.

USP - São Carlos

Fevereiro/2008 
Um Algoritmo Evolutivo para Aprendizado On-line em Jogos Eletrônicos 
Aos meus avós.

Nicolas, Emelie e Francisco (In Memoriam) e Immaculada. 
Agradecimentos

Deixo aqui meus agradecimentos a algumas pessoas valiosas que contribuíram de maneira direta ou indireta na conclusão deste trabalho.

Ao professor Mário de Castro Andrade Filho que muito me auxiliou com o método estatístico utilizado neste trabalho, muito obrigado pela sua paciência e boa vontade em me ajudar.

Ao meu orientador e amigo Eduardo do Valle Simões, que me guiou neste projetos e também em anteriores que muito contribuíram com este trabalho.

Ao meu grande amigo Francisco Krug, por compor e produzir a excelente música utilizada no jogo criado neste trabalho.

À querida Luziana Sant'Ana Simões pela ajuda com a revisão ortográfica e por acompanhar todos os meus trabalhos de perto há muito tempo, me motivando a continuar sempre.

A todos de minha família, em especial a Francisco Constantino Crocomo, Faridi Kassouf Crocomo, Lucas Kassouf Crocomo, Khalil Kassouf e Selma Khalil Kassouf, por estarem sempre me apoiando e torcendo por mim.

Para todos àqueles que leram este trabalho e deixaram suas valiosas contribuições, e também aos que sempre perguntaram sobre o andamento deste projeto: obrigado, o interesse demonstrado por vocês foi responsável pela qualidade que pude atingir neste trabalho. Espero que gostem do resultado final!

O presente trabalho foi realizado com o apoio do $\mathrm{CNPq}$, uma entidade do Governo Brasileiro voltada ao desenvolvimento científico e tecnológico. 
CROCOMO, M. K.; MIAZAKI, M.; SIMÕES, E. V. Algoritmos evolucionários no desenvolvimento de jogos adaptativos, In: Simpósio Brasileiro de Jogos Para Computador e Entretenimento Digital - WJogos ; Workshop Brasileiro de Jogos e Entretenimento Digital, 4, Anais do WJOGOS 2005, São Paulo, SP : Zuffo, M. R. et al, pp. 342 - 347, 2005.

CROCOMO, M. K. Desenvolvimento de um Ecossistema Artificial Utilizando Algoritmos Evolutivos como Ambiente de Teste para Sistemas Multi-Robô. Monografia de Conclusão de Curso. USP: Universidade de São Paulo, 2006. 49 p.

CROCOMO, M. K. Desenvolvimento de um Jogo Adaptativo Utilizando um Algoritmo Evolutivo. Monografia de Conclusão de Curso. USP: Universidade de São Paulo, 2006. 39 p.

CROCOMO, M. K.; MIAZAKI, M.; SIMÕES, E. V. Algoritmos Evolutivos para a produção de NPCs com Comportamentos Adaptativos, In: Simpósio Brasileiro de Jogos Para Computador e Entretenimento Digital - SBGames ; Anais da SBGames 2007, São Leopoldo, PA, 2007. 


\section{RESUMO}

Este trabalho verifica a possibilidade de se aplicar Algoritmos Evolutivos no aprendizado on-line de jogos. Alguns autores concordam que Algoritmos Evolutivos não são aplicáveis na prática para se atingir o objetivo em questão. É com a intenção de contestar a veracidade desta afirmação que foi desenvolvido o presente trabalho. Para atingir o objetivo proposto, foi desenvolvido um jogo de computador, no qual o algoritmo de aprendizado gera estratégias inteligentes e adaptativas para os caracteres não controlados pelo jogador através de um algoritmo evolutivo. Desta forma, a função do algoritmo evolutivo é fazer com que a estratégia utilizada pelo computador se adapte à estratégia utilizada pelo usuário a cada vez

que joga. É apresentada uma revisão bibliográfica a respeito de Computação Evolutiva e as técnicas utilizadas para implementar comportamentos inteligentes para os caracteres controlados por computador nos jogos atuais, esclarecendo suas vantagens, desvantagens e algumas possíveis aplicações. São também explicados o jogo e os algoritmos implementados, assim como os experimentos realizados e seus resultados. Por fim, é feita uma comparação do algoritmo evolutivo final com uma outra técnica de adaptação, chamada Dynamic Scripting. Assim, este trabalho oferece contribuições para o campo de Computação Evolutiva e Inteligência Artificial aplicada a jogos. 


\section{ABSTRACT}

The goal of this work is to verify if it is possible to apply Evolutionary Algorithms to online learning in computer games. Some authors agree that evolutionary algorithms do not work properly in that case. With the objective of contesting this affirmation, this work was performed. To accomplish the goal of this work, a computer game was developed, in which the learning algorithm must create intelligent and adaptive strategies to control the non-player characters using an evolutionary algorithm. Therefore, the aim of the evolutionary algorithm is to adapt the strategy used by the computer according to the player's actions during the game. A review on Evolutionary Computation and the techniques used to produce intelligent behaviors for the computer controlled characters in modern game is presented, exposing the advantages, the problems and some applications of each technique. The proposed game is also explained, together with the implemented algorithms, the experiments and the obtained results. Finally, it is presented a comparison between the implemented algorithm and the Dynamic Script technique. Thus, this work offers contributions to the fields of Evolutionary Computation and Artificial Intelligence applied to games. 


\section{SUMÁRIO}

Página

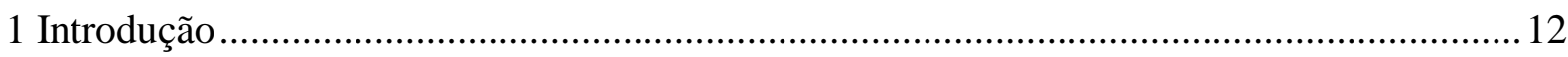

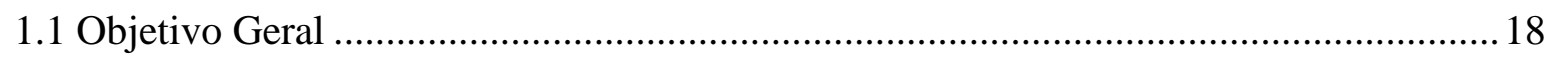

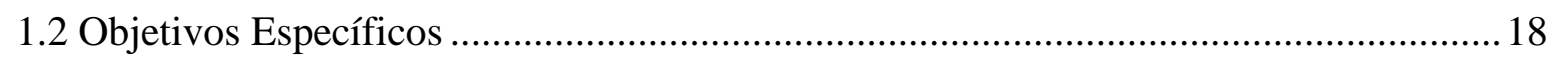

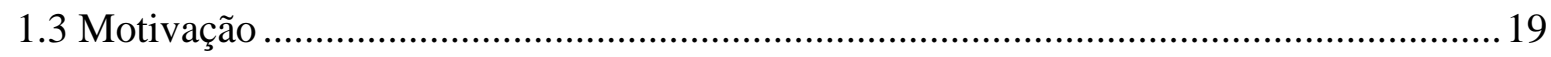

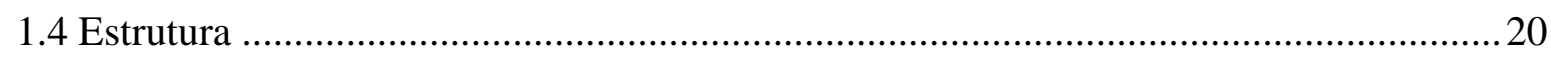

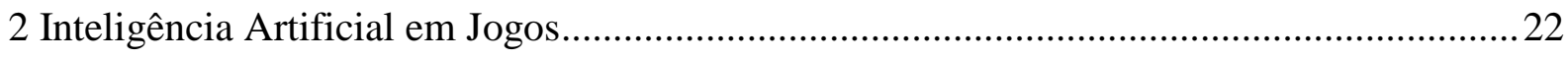

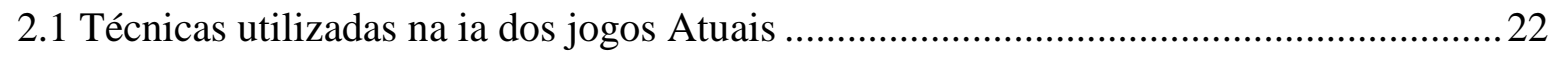

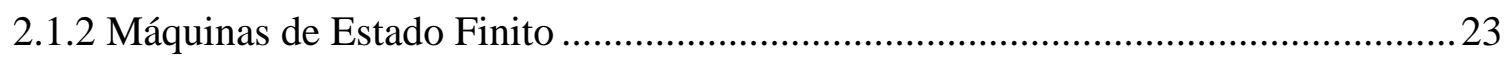

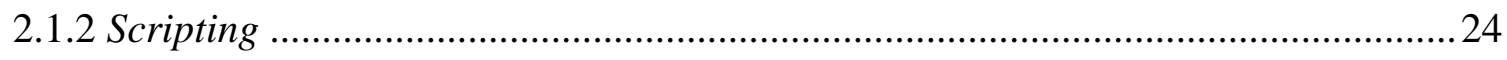

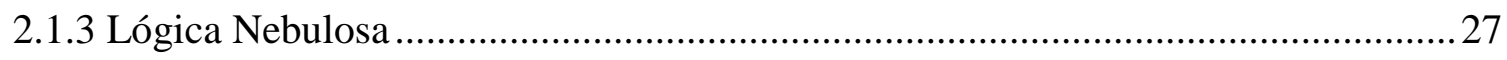

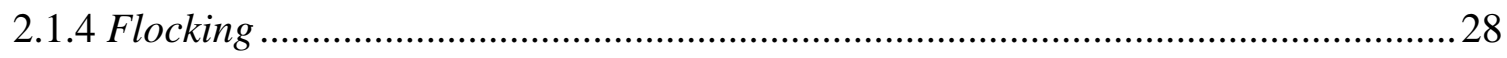

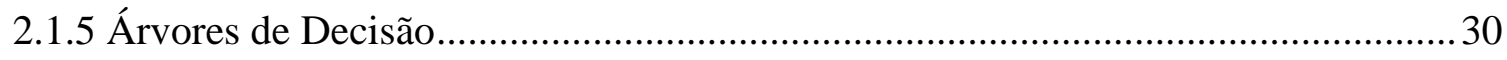

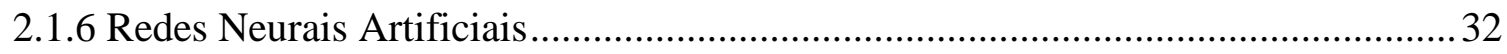

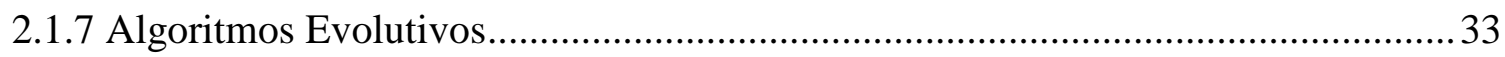

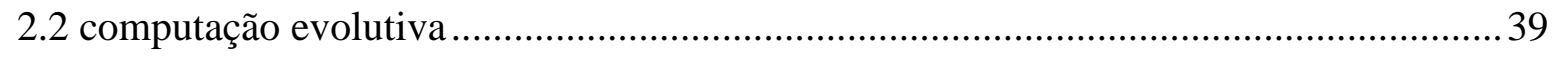

3 ambiente de Aprendizado On-line em Jogos Eletrônicos..................................................4 
4 Os experimentos

6 Conclusões.

Apêndice I - Tabela com Resultados da Técnica DS, Extraída do Artigo [13] 93 Anexo I - Pontos de Equilíbrio Resultantes do Teste Realizado Confrontando as Técnicas AE e DS .94

Anexo II - Resultados Obtidos nos Últimos Experimentos. 95 


\section{ÍNDICE DE FIGURAS}

Página

Figura 1 - Black \& White 2 à esquerda, e The Sims à direita (extraídas de [4] e [5]) 12

Figura 2 - Estrutura básica de um AE. 40

Figura 3- Exemplo de Crossover 41

Figura 4 - Um Exemplo de Mutação. 42

Figura 5 - Cenário do jogo proposto. 45

Figura 6 - Fluxograma de controle do personagem que possui o script da 49

Figura 7 - O processo do $D S$ (extraído e traduzido de [13]) 51

Figura 8 - O cromossomo proposto 54

Figura 9 - Funcionamento do AE. 55

Figura 10 - Torneio realizado para seleção dos valores iniciais de um cromossomo..... 55

Figura 11 - Exemplo do crossover proposto. 58

Figura 12 - Caso específico de crossover: a primeira regra do segundo script recebe o parâmetro do cromossomo associado para não possuir regras repetidas. .59

Figura 13 - Exemplo da mutação proposta 60

Figura 14 - DS Disputando Contra a Estratégia Ofensiva, Gráfico de Aptidão por Partida....67 
Figura 15 - DS Disputando Contra a Estratégia Ofensiva, Gráfico de Média Móvel Aptidão por Partida 69

Figura 16 - AE Disputando Contra a Estratégia Ofensiva, Gráfico de Média Móvel Aptidão por Partida 69

Figura 17 - AE Disputando Contra a Técnica DS, Gráfico de Média Móvel Aptidão por Partida. 75

Figura 18 - Método Adotado para a Coleta dos Dados .76

Figura 19 - Frequiência de Vitórias das Técnicas AE e DS em 2000 Partidas....... 78

Figura 20 - Comparação das freqüências de vitórias entre o AE implementado e técnica DS. Resultados coletados utilizando 300, 200, 100 e 50 partidas por jogo. 79 
ÍNDICE DE TABELAS

Página

Tabela I - Técnicas de IA utilizadas em Jogos, extraída de [3] 15

Tabela II - Trabalhos realizados com FSMs aplicadas a jogos.

Tabela III - Trabalhos realizados com Scriptings em jogos 26

Tabela IV - Trabalhos realizados com Lógica Nebulosa em Jogos 28

Tabela V - Trabalhos sobre a técnica Flocking 30

Tabela VI - Trabalhos com Árvores de Decisão 31

Tabela VII - Trabalhos realizados com Redes Neurais em Jogos 33

Tabela VIII - Trabalhos Realizados com Algoritmos Evolutivos em Jogos 35

Tabela IX - Sumários das técnicas utilizadas em jogos, baseado em [3] 38

Tabela X - Exemplo de um script .46

Tabela XI - Resultados obtidos confrontando os scripts desenvolvidos pela técnica DS com as estratégias pré-elaboradas da primeira coluna. 71

Tabela XII - Resultados obtidos confrontando os scripts desenvolvidos pelo AE com as estratégias pré-elaboradas da primeira coluna. .72

Tabela XIII - Pontos de Equilíbrio obtidos pelo AE ao confrontar a técnica DS .74

Tabela XIV - Pontos de Equilíbrio obtidos pela técnica DS ao confrontar o AE. .74 
Tabela XV - Verificação da superioridade da técnica DS, na inequação apresentada, FVA e FVB representam a percentagem de vitórias da técnica DS e AE respectivamente. Os termos $e a$ e $e b$ representam, nesta ordem, os erros amostrais de FVA e FVB. 81

Tabela XVI - Verificação da superioridade do AE implementado, na inequação apresentada, FVA e FVB representam a percentagem de vitórias das técnicas AE e DS respectivamente. Os termos ea e eb representam, nesta ordem, os erros amostrais de FVA

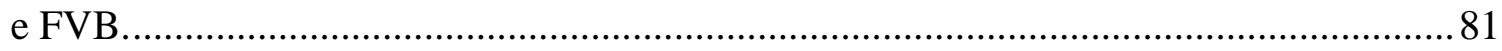

Tabela XVII - Pontos de equilíbrio obtidos pela técnica Dynamic Scripting, extraída e traduzida de [13] 93

Tabela XVIII - Pontos de equilíbrio obtidos do confronto entre as técnicas AE e DS 94

Tabela XIX - Freqüência de vitórias e erro máximo obtido nos experimentos realizados confrontando as técnicas AE e DS em 2000, 300, 200, 100 e 50 partidas 95 


\section{GLOSSÁRIO}

Adaptação. Melhoria do valor de aptidão (fitness) presente no passar das gerações.

AE. Algoritmo Evolutivo. Algoritmos relacionados à Computação Evolutiva. Englobam os algoritmos Genéticos, mas não se resumem a estes. Inspirados na Teoria da Evolução Natural de Charles Darwin.

\section{Algoritmo Evolutivo. AE.}

Aprendizado On-line. Em jogos com aprendizado on-line a adaptação do jogo ocorre durante a interação com o usuário.

Aprendizado Off-line. Em jogos com aprendizado off-line $\mathrm{O}$ aprendizado ocorre durante a produção do jogo.

Aptidão. Pontuação que indica a eficácia da solução encontrada.

Cromossomo. Solução candidata, utilizada pelo Algoritmo Evolutivo em seu processo de busca.

Crossover. Mecanismo da biologia abstraído na forma de uma função matemática utilizada pelo Algoritmo Evolutivo, aplicada sobre os cromossomos. Faz com que uma nova solução possua características de soluções anteriores.

CRPG. Computer role-playing game, Estilo de Jogo para Computador. São exemplos destes jogos: Baldur's Gate, Neverwinter Nights.

DS. Dynamic Scripting. Algoritmo criado para agir no aprendizado on-line em jogos.

Dynamic Scripting. DS.

ESA. Entertainment Software Association, Associação de Software de Entretenimento.

Fitness. O mesmo que aptidão: pontuação que indica a eficácia da solução encontrada.

FSM - Finite State Machines, Máquinas de Estado Finito. 
Geração. O conjunto das soluções contidas em uma população em um determinado instante; sempre que os operadores evolutivos criam uma nova população, com novas soluções, diz-se que uma nova geração foi iniciada.

IA. Inteligência Artificial.

Jogos em Primeira Pessoa. Estilo de Jogo para Computador. São exemplos destes jogos: Doom, Quake.

MUD - Multi-User Dungeon, Domain or Dimension, Dungeon, Domínio ou Dimensão MultiUsuário: primeiros RPGs eletrônicos.

Mutação. Mecanismo da biologia abstraído na forma de uma função matemática utilizada pelo Algoritmo Evolutivo, aplicada sobre os cromossomos. Insere variedade nas soluções da população.

Operadores Evolutivos. Funções utilizadas pelo Algoritmo Evolutivo, como a mutação e o crossover.

População. Conjunto de possíveis soluções sendo testadas e evoluídas pelo Algoritmo Evolutivo.

RNA. Redes Neurais Artificiais.

RPG. Role-Playing Game, Jogo de interpretação de papéis. 


\section{INTRODUÇÃO}

Douglas Lowenstein, o presidente da ESA [1] (Entertainment Software Association), tem argumentado que a indústria do videogame vem fundindo tecnologia e criatividade para produzir alguns dos melhores entretenimentos do século 21. Nos últimos anos, muita ênfase foi dada ao realismo dos jogos eletrônicos, fazendo surgir uma variedade de motores gráficos, físicos, de áudio e de Inteligência Artificial (IA) [2]. Grandes esforços foram empregados principalmente na ambientação gráfica utilizada. Em 2002, Sweetser [3] disse que o próximo foco no mercado de jogos seria a elaboração de personagens que se comportam de forma realista e podem aprender e se adaptar, ao invés de personagens com maiores resoluções e com mais frames por segundo.

Atualmente empresas como a Eletronic Arts apostam no aprimoramento da inteligência artificial utilizada em seus jogos para comandar os personagens não controlados pelo jogador. Em função disso, alguns jogos têm se destacado pela qualidade de sua Inteligência Artificial (IA), como Black \& White e The Sims (ver Figura 1).
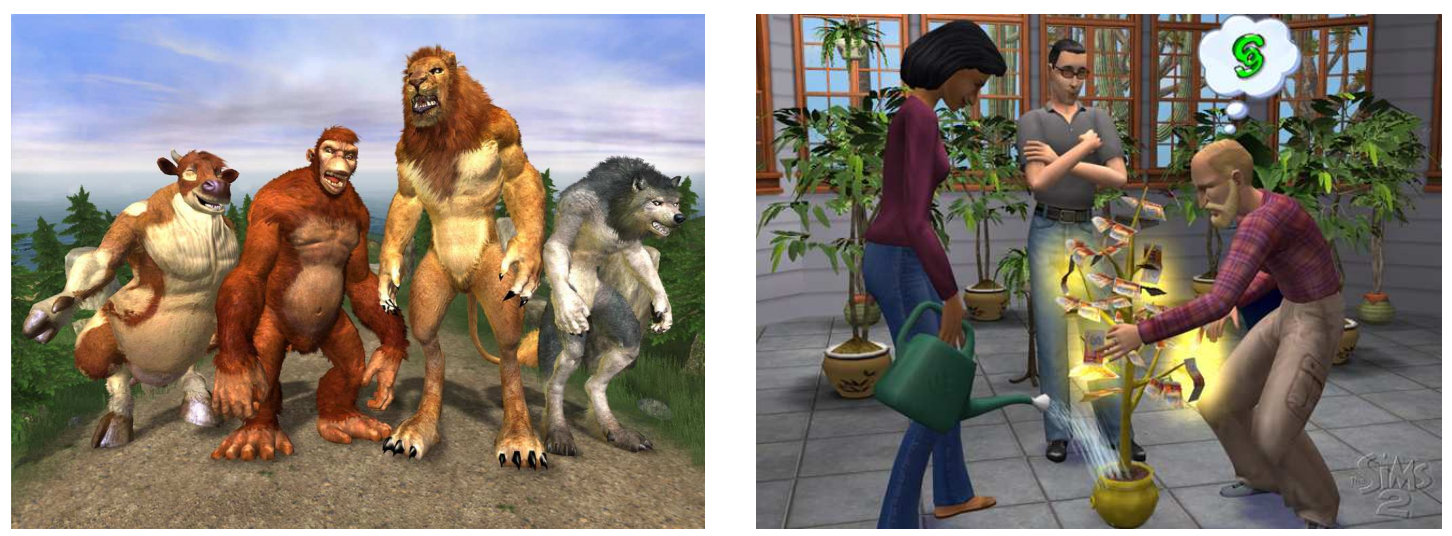

Figura 1 - Black \& White 2 à esquerda, e The Sims à direita (extraídas de [4] e [5]) 
Máquinas de estado finito vêm sendo empregadas na elaboração das estratégias utilizadas pelo computador com uma frequência maior do que outros métodos nos jogos atuais [6]. Isto se deve ao fato de serem fáceis de implementar e geralmente suficientes para atingir o propósito desejado. No entanto, esta técnica torna previsível a estratégia utilizada pelo computador. Além das máquinas de estado finito, várias técnicas são utilizadas na IA em jogos de computador, dentre as quais podem ser citadas:

- Scriptings [7]: linguagens de programação em alto nível, utilizadas para permitir a programação de comportamentos por não programadores. Através desta técnica o próprio jogador pode programar o comportamento de seus personagens.

- Lógica Fuzzy [8]: Nos jogos o papel desta técnica é normalmente limitado a complexos comandos condicionais. É utilizada na seleção de comportamentos e tomadas de decisão. Esta técnica pode permitir, por exemplo, o cálculo de um “nível de medo" de um personagem com relação ao jogador.

- Flocking [9]: Simulação de comportamentos naturais de grupos de indivíduos, como um grupo de pássaros ou um rebanho de ovelhas. Utilizada para criar ambientes realistas a serem explorados pelo jogador.

- Aprendizado através de Árvore de Decisão [10]: Utilizada para classificação ou predição. Permite encontrar a sequiência de ações que provavelmente apresenta os melhores resultados para uma determinada situação. Apesar de não ser uma técnica muito explorada em jogos, árvores de decisão são de fácil implementação.

- Redes Neurais Artificiais (RNA) [11]: Normalmente possuem como objetivo que o computador aprenda a imitar o comportamento do jogador. Alguns autores [3] 
afirmam que Redes Neurais Artificiais ainda irão desempenhar um importante papel na construção de jogos comerciais.

- Algoritmos Evolutivos (AEs) [12]: Possuem diversas aplicações em jogos, como por exemplo adaptar as estratégias utilizadas pelo computador em relação as estratégias utilizadas pelo usuário, encontrar caminhos e evoluir comportamentos de personagens controlados pelo computador. Apesar das aplicações para Algoritmos Evolutivos serem numerosas, os mesmos encontram resistência em serem utilizados pelos desenvolvedores de jogos, pois alguns autores afirmam que esta técnica (assim como a técnica de Redes Neurais Artificiais) permite a obtenção de comportamentos "não aceitáveis" durante o processo de aprendizado dos personagens [13].

Uma lista destas técnicas, com exemplos de jogos nos quais foram utilizadas é apresentada na Tabela I abaixo. É importante ressaltar que embora estas técnicas tenham sido selecionadas para estudo neste trabalho, existem várias outras técnicas utilizadas na Inteligência Artificial dos jogos atuais. Como exemplo, técnicas de aprendizado por reforço [14] e técnicas para resolver problemas de busca, como os algoritmos A* (lê-se A "estrela") e mini-max. Os livros [15] e [16] oferecem um bom nível de detalhamento sobre IA e jogos, e são sugeridos para encontrar informações complementares às deste trabalho. 
Tabela I - Técnicas de IA utilizadas em Jogos, extraída de [3]

\begin{tabular}{|c|c|}
\hline Técnica & Jogos \\
\hline Máquinas de Estado Finito & $\begin{array}{l}\text { - Age of Empires } \\
\text { - Half Life } \\
\text { - Doom } \\
\text { - Quake }\end{array}$ \\
\hline Scripting & $\begin{array}{l}\text { - Black \& White } \\
\text { - Unreal } \\
\text { - Dark Reign } \\
\text { - Baldur's Gate }\end{array}$ \\
\hline Lógica Fuzzy & $\begin{array}{l}\text { - Swat } 2 \\
\text { - Call to Power } \\
\text { - Close Combat } \\
\text { - Petz } \\
\text { - The Sims }\end{array}$ \\
\hline Flocking & $\begin{array}{l}\text { - Half-Life } \\
\text { - Unreal } \\
\text { - Enemy Nations }\end{array}$ \\
\hline Árvores de Decisão & - Black \& White \\
\hline Redes Neurais & $\begin{array}{l}\text { - Black \& White } \\
\text { - BC3K } \\
\text { - Creatures } \\
\text { - Heavy Gear }\end{array}$ \\
\hline Algoritmos Evolutivos & $\begin{array}{l}\text { - Cloack, Dagger \& DNA } \\
\text { - Creatures } \\
\text { - Return to Fire II }\end{array}$ \\
\hline
\end{tabular}


As técnicas de IA permitem, entre outras aplicações, que o jogo apresente uma adaptação ao usuário. A adaptação em um jogo pode ser realizada de dois modos distintos [17]:

- Adaptação Indireta: comportamentos pré-programados são alternados baseados em estatísticas do jogo. Tanto a escolha de quais estatísticas serão utilizadas, quanto a escolha das mudanças que irão ocorrer são feitas pelo programador do jogo. Esta adaptação se limita a extrair informação do jogo, através da qual um comportamento já existente é selecionado para os agentes controlados pelo computador. Um exemplo de adaptação Indireta é a seleção automática de um nível de dificuldade baseado em estatísticas que medem a habilidade apresentada pelo jogador.

- Adaptação Direta: age diretamente na criação de novos comportamentos para os agentes. Utiliza algoritmos de otimização e aprendizado por reforço para alterar os comportamentos utilizados nas bases que afetam o desempenho do jogador. Adaptação Direta é difícil de controlar, e, além disso, é necessário encontrar uma medida adequada de desempenho a ser utilizada - o que não é uma tarefa de fácil execução. No entanto, esta forma de adaptação apresenta as seguintes vantagens: não limitar os comportamentos possíveis dos agentes do jogo e necessitar de pouco conhecimento do programador a respeito de bons comportamentos.

A Inteligência Artificial em jogos apresenta técnicas de aprendizado de máquina que podem ser utilizadas on-line ou off-line. No aprendizado off-line não há a intervenção de um jogador humano para que o aprendizado ocorra e, portanto, pode ser realizado em modo batch ou até mesmo antes do jogo ser lançado, durante sua produção. Desta forma, as estratégias 
pré-programadas disputam entre si, e a técnica de aprendizado empregada visa a obtenção de estratégias melhores para serem utilizadas no jogo produzido.

No aprendizado on-line, a adaptação depende de uma interação com o usuário, e, portanto ocorre durante a execução do jogo, e não na elaboração do mesmo, ou seja, após o jogo ter sido lançado comercialmente. Tal aprendizado permite a adaptação da estratégia utilizada pelo computador em relação ao comportamento do jogador. P. Spronck [13] afirma em seu trabalho que Algoritmos Evolutivos não são candidatos a serem utilizados no aprendizado online em jogos, pois não satisfazem os dois últimos dos quatro requisitos apresentados por ele:

- Rápido: O algoritmo de aprendizado deve ser computacionalmente rápido, pois é realizado durante a execução do jogo. Desta forma, um algoritmo lento atrapalha o desempenho do jogo.

- Robusto: O mecanismo de aprendizado deve suportar uma quantidade de aleatoriedade significante, normalmente presente nos jogos comerciais.

- Efetivo: As estratégias adaptadas devem ser pelo menos tão desafiadoras quanto as programadas explicitamente. Como consequiência, o mecanismo de aprendizado deve gerar estratégias mais eficientes. P. Spronck afirma que este requisito exclui métodos de aprendizado aleatórios, como os Algoritmos Evolutivos, que permitem a geração de estratégias muito ruins para serem utilizadas contra o jogador.

- Eficiente: Um pequeno conjunto de testes deve ser suficiente para que o aprendizado ocorra. P. Spronck diz que este requisito exclui técnicas de aprendizado lento, como Redes Neurais, Algoritmos Evolutivos e Aprendizado por Reforço, que tomariam muito tempo dos jogadores para poderem ajustar suas estratégias. 


\subsection{OBJETIVO GERAL}

O presente trabalho visa aplicar um Algoritmo Evolutivo (AE) no aprendizado on-line de um jogo, no qual o computador combina percepção e cognição dos caracteres não controlados pelo jogador através de um AE para o desenvolvimento de estratégias inteligentes e adaptativas de controle dos personagens autônomos em ambientes dinamicamente mutáveis. O objetivo principal do trabalho é o de testar a validade das afirmações feitas por P. Spronck em [13], construindo um AE tentando satisfazer os quatro requisitos (rapidez, efetividade, robustez e eficiência) para um aprendizado on-line que de fato funcione, obtendo então a resposta para a seguinte pergunta:

É possível construir um AE para o aprendizado on-line de jogos que possa ser utilizado na prática, por satisfazer os requisitos de rapidez, efetividade, robustez e eficiência?

Para alcançar este objetivo, foram implementadas e testadas técnicas direcionadas à resolução de problemas encontrados no ambiente de jogos, como co-evolução, adaptação em tempo real, otimização multiobjetivo e evolução de pequenas populações de indivíduos.

\subsection{OBJETIVOS ESPECÍFICOS}

Para viabilizar o desenvolvimento do trabalho proposto, alguns objetivos específicos precisaram ser realizados:

1. Modelagem e programação de um jogo que se mostre um bom ambiente para os testes do AE. 
2. Desenvolvimento de um AE adequado ao jogo construído, capaz de produzir soluções adaptativas para os problemas encontrados.

3. Implementação da técnica Dynamic Scripting para posterior comparação.

4. Comparação do AE desenvolvido com as técnicas que satisfaçam os quatro requisitos para um algoritmo de aprendizado online, como a Dynamic Scripting desenvolvida por P. Spronck, buscando finalmente responder a pergunta apresentada em 1.1 (Objetivo Geral).

\subsection{MOTIVAÇÃO}

Este trabalho visa elaborar um AE para adaptar as estratégias utilizadas pelo computador às estratégias adotadas pelo jogador. Este mecanismo possui como propósito proporcionar novas experiências e desafios ao jogador a cada vez que joga.

O desenvolvimento de jogos comerciais apresenta problemas de grande interesse para pesquisadores de Inteligência Computacional. Vários destes problemas são comuns de se encontrar em diversas aplicações de Algoritmos Evolutivos: co-evolução [18], otimização multiobjetivo [19] e evolução de pequenas populações de indivíduos [20]. Por esta razão, jogos são freqüentemente utilizados como plataforma de teste para a construção e configuração de AEs, como exemplo o jogo "Cellz" [21].

Embora os Algoritmos Evolutivos tenham sido exaustivamente explorados no meio acadêmico, os mesmos encontram resistência para serem aceitos no desenvolvimento de jogos devido ao fato de pesquisadores apontarem a técnica como lenta e capaz de permitir a obtenção de desempenhos ruins [3] [13]. 
Ainda que AEs apresentem resistência para serem aceitos pelos desenvolvedores de jogos, alguns pesquisadores [3] reconhecem que tais algoritmos podem ser boas alternativas em áreas nas quais técnicas tradicionais de IA para jogos encontram dificuldades. Assim, este trabalho pretende contribuir com as áreas de Algoritmos Evolutivos e Inteligência Artificial em jogos. São exemplos de aplicações de AEs em jogos:

- Adaptação de estratégias do computador para explorar fraquezas do jogador em jogos de estratégia em tempo real.

- Definição de comportamentos individuais em jogos de estratégia em tempo real, ao invés da definição da estratégia de um grupo de personagens.

- Evolução de comportamentos de personagens em CRPGs (Computer Role-Playing Games) ou jogos em primeira pessoa.

- Obtenção de caminhos a serem percorridos por agentes do jogo.

\subsection{ESTRUTURA}

Este trabalho está disposto em capítulos organizados da seguinte forma:

Capítulo 2: Inteligência Artificial em Jogos - Apresenta uma revisão sobre as técnicas utilizadas na Inteligência Artificial de jogos atuais, explica as vantagens, desvantagens e aplicações das seguintes técnicas: Máquinas de Estado Finito, Scripting, Lógica Nebulosa, Flocking, Árvores de Decisão, Redes Neurais Artificiais e Algoritmos Evolutivos. Trabalhos envolvendo tais técnicas são apresentados e são explicadas as razões para a escolha de AEs

para implementar aprendizado no modelo de jogo proposto. Neste capítulo também é 
explicada a operação de um AE conforme está implementado neste trabalho, citando as principais técnicas utilizadas e mostrando exemplos de seus operadores evolutivos.

Capítulo 3: O Ambiente de Aprendizado On-line em Jogos Eletrônicos - Explica o Jogo e os Algoritmos propostos que foram implementados para a execução do trabalho: $\mathrm{O} A E$ proposto assim como a técnica Dynamic Scripting são descritos, e são realizadas observações sobre o espaço de busca do problema sendo tratado.

Capítulo 4: Os Experimentos - Este capítulo explica a metodologia experimental adotada para verificar se o AE implementado satisfaz todos os requisitos para um aprendizado on-line que funcione de fato.

Capítulo 5: Resultados Obtidos - Explica os procedimentos que foram executados para a realização da coleta dos dados, que são avaliados ainda neste mesmo capítulo.

Capítulo 6: Conclusões- Neste capítulo são discutidas as conclusões acerca dos resultados encontrados, dificuldades encontradas durante a realização do projeto, objetivos atingidos assim como suas contribuições dentro do estado da arte, e por fim são sugeridas possíveis continuações para este trabalho. 


\section{INTELIGÊNCIA ARTIFICIAL EM JOGOS}

Nos últimos 25 anos, os esforços empreendidos pela indústria de jogos se concentraram principalmente na tecnologia gráfica produzida, permitindo a criação de mundos realistas com gráficos 3d e avançadas engines físicas [12]. No entanto, sofisticadas técnicas de IA em jogos estão começando a ser utilizadas apenas atualmente. As técnicas de IA utilizadas com maior freqüência pela indústria de jogos são muito simples quando comparadas àquelas exploradas pelo meio acadêmico e utilizadas em aplicações industriais [22]. Algumas das razões para isto são apontadas abaixo:

- Grande parte do processamento do computador é reservado para outras funções, principalmente para a renderização de imagens. Poucos recursos do computador são disponibilizados para a IA dos jogos [22].

- A comunidade de desenvolvedores de jogos apresenta resistência à utilização de métodos não determinísticos, como Algoritmos Evolutivos e Redes Neurais [3].

- Falta de tempo disponibilizado para o desenvolvimento da IA, pois normalmente a IA era adicionada apenas após outras partes do jogo terem sido implementadas, como, por exemplo, seus motores gráficos [22] [2].

\subsection{TÉCNICAS UTILIZADAS NA IA DOS JOGOS ATUAIS}

Foi apenas recentemente que os desenvolvedores de jogos passaram a atentar para a importância financeira que técnicas de IA mais complexas exercem sobre seus produtos [12]. 
Atualmente, jogos como o Black \& White 2, o The Sims, e o Spore ${ }^{1}$ investem grandes esforços nas técnicas de IA utilizadas. Devido a essa importância, diferentes técnicas vêm sendo pesquisadas e utilizadas para a IA em jogos, algumas das quais serão explicadas a seguir.

\subsubsection{Máquinas de Estado Finito}

Máquinas de Estado Finito [23] (ou Finite State Machines - FSM - em inglês) são utilizadas em jogos com maior frequiência do que qualquer outra técnica de Inteligência Artificial [3]. Isto se deve ao fato de tal técnica ser de fácil implementação e depuração, apresentarem baixa complexidade e serem suficientes para satisfazer as necessidades do jogo. A idéia principal desta técnica é a de dividir o jogo em estados, cada um contendo suas possíveis transições para outros estados, baseadas no comportamento do jogo. No entanto, por ser determinística, esta técnica torna previsível a estratégia utilizada pelo computador [6].

Um desafio encontrado ao se utilizar FSMs é o de que todas as possíveis situações do jogo devem ser antecipadas. Além disso, o tamanho do diagrama de estados tende a aumentar muito durante o desenvolvimento do jogo, tornando a manutenção da FSM difícil, pois a mesma apresenta uma fraca escalabilidade e geralmente é fracamente estruturada [3].

FSMs permitem que sejam armazenados tanto os estados dos personagens do jogo, como do ambiente. Desta forma, torna-se possível gerenciar tanto o cenário do jogo quanto seus

\footnotetext{
${ }^{1}$ Eletronic Arts. Spore. Disponível em: <http://www.spore.com/>. Acesso em: 12 fev. 2008.
} 
personagens. Exemplos de trabalhos realizados com Máquinas de Estado Finito em jogos são apresentados pela Tabela II.

Tabela II - Trabalhos realizados com FSMs aplicadas a jogos.

\begin{tabular}{|c|c|c|}
\hline Título & & Informações \\
\hline \multirow{3}{*}{$\begin{array}{l}\text { Inteligência Artificial } \\
\text { em Jogos de Tiro em } \\
\text { Primeira Pessoa [24] }\end{array}$} & Instituição & $\begin{array}{l}\text { CCFT - Centro de Ciências Formais e Tecnologia } \\
\text { Unit - Universidade Tiradentes }\end{array}$ \\
\hline & Local & Brasil - Aracaju - SE \\
\hline & Descrição & $\begin{array}{l}\text { Este trabalho mostra como a técnica Máquinas de Estado } \\
\text { Finito pode ser utilizada em jogos de tiro em primeira } \\
\text { pessoa. }\end{array}$ \\
\hline \multirow{3}{*}{$\begin{array}{l}\text { An Object Oriented } \\
\text { Approach for } \\
\text { Hierarchical State } \\
\text { Machines }[25]\end{array}$} & Instituição & Departamento de Informática - PUC-Rio \\
\hline & Local & Brasil \\
\hline & Descrição & $\begin{array}{l}\text { Neste trabalho é mostrada uma técnica que consiste em } \\
\text { adaptar conceitos de orientação a objetos ao uso de } \\
\text { Máquinas de Estado Finito Hierárquicas para aumentar a } \\
\text { produtividade do desenvolvimento de FSMs em } \\
\text { videogames. }\end{array}$ \\
\hline \multirow{3}{*}{$\begin{array}{l}\text { Behavior Planning } \\
\text { for Character } \\
\text { Animation }[26]\end{array}$} & Instituição & $\begin{array}{l}\text { School of Computer Science } \\
\text { Carnegie Mellon University }\end{array}$ \\
\hline & Local & Estados Unidos da América \\
\hline & Descrição & $\begin{array}{l}\text { Neste trabalho, uma FSMs foi construída abstraindo } \\
\text { movimentos dos personagens em comandos de alto nível, } \\
\text { com o objetivo de criar comportamentos realistas para os } \\
\text { mesmos. }\end{array}$ \\
\hline
\end{tabular}

\subsubsection{Scripting}

Assim como FSMs, Scripting [7] é uma técnica muito popular entre os desenvolvedores de jogos. Tal mérito se deve ao fato de scripts serem fáceis de entender, de implementar e de serem utilizados por usuários sem experiência em programação. Scripting é uma linguagem 
de programação criada para simplificar uma tarefa complexa para um programa em particular. Geralmente, scripts são criados de forma a lembrar uma linguagem natural, como, por exemplo, o inglês. Podem ser utilizados em várias partes do jogo por diferentes pessoas:

- O roteirista pode utilizar scripts para implementar suas histórias.

- Artistas gráficos usam scripts para automatizar processos repetitivos de animação.

- O programador pode definir nos scripts os comportamentos a serem tomados pelos personagens do jogo.

- Caso o sistema de script seja exposto ao público, os próprios jogadores podem utilizar o script para personalizar seus personagens.

Esta grande quantidade de aplicações para a técnica é possível pois a linguagem scripting é normalmente separada dos dados do jogo. Desta forma, é criado um ambiente seguro para que não programadores realizem mudanças no programa.

Scriptings compartilham com FSMs as desvantagens de previsibilidade (pois são também determinísticos) e de necessitar a antecipação de todas as possíveis situações do jogo [3]. Apesar destas desvantagens, uma grande quantidade de jogos desenvolve seus próprios scripts, como, por exemplo, o NWScript, utilizado no famoso jogo Neverwinter Nights ${ }^{2}$ [27].Tentando resolver o problema da previsibilidade dos scripts, um grupo de pesquisadores desenvolveu uma técnica chamada Dynamic Scripting que está explicada mais adiante no capítulo 3.2.1. Na Tabela III encontram-se alguns trabalhos realizados com Scriptings em jogos.

\footnotetext{
${ }^{2}$ Bioware - Neverwinter Nights, http://nwn.bioware.com/ , último acesso em 12/02/2008
} 
Tabela III - Trabalhos realizados com Scriptings em jogos

\begin{tabular}{|c|c|c|}
\hline Título & & Informações \\
\hline \multirow{3}{*}{$\begin{array}{l}\text { Code Generation for } \\
\text { AI Scripting in } \\
\text { Computer Role- } \\
\text { Playing Games }[27]\end{array}$} & Instituição & Department of Computing Science, University of Alberta \\
\hline & Local & Canadá \\
\hline & Descrição & $\begin{array}{l}\text { É apresentado um modelo de se gerar scripts chamado } \\
\text { ScriptEase. Este modelo permite que mundos complexos } \\
\text { sejam construídos sem a necessidade de programá-los } \\
\text { explicitamente. É feita uma demonstração da ferramenta } \\
\text { gerando código para o jogo Neverwinter Nights. }\end{array}$ \\
\hline \multirow{3}{*}{$\begin{array}{l}\text { Interactive Story } \\
\text { Writing in the } \\
\text { Classroom: } \\
\text { Using Computer } \\
\text { Games }[28]\end{array}$} & Instituição & Department of Education, University of Alberta \\
\hline & Local & Canadá \\
\hline & Descrição & $\begin{array}{l}\text { Para testar a usabilidade da ferramenta ScriptEase, foi } \\
\text { feito um experimento com o Colégio de Alberta. Este } \\
\text { trabalho reporta as experiências realizadas com a } \\
\text { ferramenta em sala de aula. }\end{array}$ \\
\hline \multirow{3}{*}{$\begin{array}{l}\text { SCREAM: Scripting } \\
\text { Emotion based } \\
\text { Agent Minds [29] }\end{array}$} & Instituição & $\begin{array}{l}\text { Dept. of Information and Communication Eng. } \\
\text { Graduate School of Information Science and } \\
\text { Technology, University of Tokyo }\end{array}$ \\
\hline & Local & Japão \\
\hline & Descrição & $\begin{array}{l}\text { É apresentada a ferramenta } S C R E A M \text {, que permite que } \\
\text { desenvolvedores gerem respostas sociais e emocionais } \\
\text { para personagens animados graficamente. }\end{array}$ \\
\hline
\end{tabular}




\subsubsection{Lógica Nebulosa}

A Lógica Nebulosa, também conhecida como Lógica Fuzzy, foi introduzida em 1965 por Lofti Zadeh [8].O papel da Lógica Nebulosa nos jogos atuais geralmente não ultrapassa complexos comandos condicionais (comandos do tipo se-então-senão) [3]. Isto se deve à dificuldade de se criar sistemas de Lógica Nebulosa. Os benefícios da Lógica Nebulosa vêm do fato da mesma poder utilizar informações incompletas ou errôneas, o que não pode ser feito com a lógica booleana. Além de trabalhar com os valores de verdade e falsidade utilizados na lógica clássica, representados pelos valores inteiros 0 e 1, a Lógica Nebulosa trabalha com valores reais intermediários, representando desta forma informações vagas. Sendo assim, a Lógica Nebulosa complementa a Lógica Clássica.

A Lógica Nebulosa pode ser utilizada nas áreas de tomada de decisão, seleções de comportamento, e como filtro de dados de entrada/saída. Normalmente é utilizada quando não existe um modelo matemático simples que possa resolver o problema, quando é necessário o conhecimento do especialista e em problemas não lineares. Utilizando esta técnica, torna-se possível trabalhar com conceitos subjetivos, como, por exemplo, o nível de afetividade de um personagem com relação ao jogador: muito baixo, baixo, médio, alto, etc. [30].

A lógica Nebulosa é também utilizada nos jogos em conjunto com as FSMs, chamadas de Máquinas de Estado Finito Nebulosas, ou FFSM (Finite Fuzzy State Machine). Nestas, as transições são baseadas em valores nebulosos, e normalmente os estados também o são. Nas FFSMs as transições não são mais determinísticas [31]. Na Tabela IV abaixo podem ser vistos exemplos de trabalhos envolvendo a utilização da Lógica Nebulosa em jogos. 
Tabela IV - Trabalhos realizados com Lógica Nebulosa em Jogos

\begin{tabular}{|c|c|c|}
\hline Título & \multicolumn{2}{|r|}{ Informações } \\
\hline \multirow{3}{*}{$\begin{array}{l}\text { Aprendizado de } \\
\text { Regras Nebulosas em } \\
\text { Tempo Real para } \\
\text { Jogos Eletrônicos } \\
\text { [32] }\end{array}$} & Instituição & $\begin{array}{l}\text { Universidade Federal do Rio de Janeiro } \\
\text { Instituto de Matemática / Núcleo de Computação } \\
\text { Eletrônica }\end{array}$ \\
\hline & Local & Brasil \\
\hline & Descrição & $\begin{array}{l}\text { Apresenta uma adaptação de um método de aprendizado } \\
\text { baseado em regras nebulosas aplicadas em sistemas de } \\
\text { tempo real, em particular, os jogos eletrônicos. As regras } \\
\text { Nebulosas neste trabalho tentam descrever a forma como } \\
\text { o usuário joga. }\end{array}$ \\
\hline \multirow{3}{*}{$\begin{array}{l}\text { Aplicação da lógica } \\
\text { Fuzzy a jogos } \\
\text { didáticos de } \\
\text { computador - a } \\
\text { Experiência do } \\
\text { mercadão gl [33] }\end{array}$} & Instituição & $\begin{array}{l}\text { Universidade Regional Integrada do Alto Uruguai e das } \\
\text { Missões - URI }\end{array}$ \\
\hline & Local & Brasil \\
\hline & Descrição & $\begin{array}{l}\text { Neste trabalho é apresentado um jogo interativo de } \\
\text { matemática que utiliza recursos computacionais } \\
\text { inteligentes para prover o professor com informações } \\
\text { sobre o desempenho do aluno dentro do ambiente virtual } \\
\text { de ensino. As ações dos usuários (alunos) são } \\
\text { monitoradas através de regras de inferência nebulosas. }\end{array}$ \\
\hline \multirow{3}{*}{$\begin{array}{l}\text { Modelagem Fuzzy } \\
\text { para um Jogo de } \\
\text { Naves Espaciais [34] }\end{array}$} & Instituição & $\begin{array}{l}\text { Universidade Federal do Rio de Janeiro - Instituto de } \\
\text { Matemática / Núcleo de Computação Eletrônica }\end{array}$ \\
\hline & Local & Brasil \\
\hline & Descrição & $\begin{array}{l}\text { Este trabalho mostra as vantagens da utilização de Lógica } \\
\text { Nebulosa durante a modelagem de um jogo. Para tanto } \\
\text { descreve um jogo de naves espaciais utilizando esta } \\
\text { técnica. }\end{array}$ \\
\hline
\end{tabular}

\subsubsection{Flocking}

O objetivo da técnica de Flocking [9] é o de simular o comportamento natural de grupos de entidades, como por exemplo, um rebanho de ovelhas. Esta técnica é utilizada para criar 
ambientes realistas para o jogador explorar em uma série de jogos comerciais (ver Tabela I). A técnica é normalmente explorada em jogos nos quais é mais importante o comportamento do time de personagens ao invés do comportamento individual [30].

Desenvolvida como uma alternativa a gerar scripts para um número grande de indivíduos, na técnica de Flocking cada indivíduo navega de acordo com sua percepção e as leis da física que governam o ambiente. Nesta técnica não existem estados, ou seja, informações não são mantidas de uma etapa para outra (economia de memória). A cada ciclo, cada personagem possui uma nova percepção do ambiente, através da qual realiza uma ação. Esta técnica é puramente reativa, e responde a mudanças no ambiente em tempo real [3].

Utilizada por jogos de primeira pessoa, como Half-Life $e^{3}$ e Unreal ${ }^{4}$ para gerar comportamentos dos grupos de personagens, e em jogos de estratégia em tempo real, como Enemy Nations ${ }^{5}$, para gerar movimentação realista dos exércitos. Embora Flocking seja uma técnica com aplicações limitadas, é uma técnica simples e eficiente para gerar movimentações realistas de grupos de indivíduos. Trabalhos utilizando a técnica de Flocking podem ser vistos na Tabela V.

\footnotetext{
${ }^{3}$ Half-Life, http://half-life.com/index.php , acessado em 31/01/2007

${ }^{4}$ Unreal, http://www.unreal.com/, acessado em 31/01/2007

${ }^{5}$ Enemy Nations, http://www.enemynations.com/ , acessado em 31/01/2007
} 
Tabela V - Trabalhos sobre a técnica Flocking

\begin{tabular}{|c|c|c|}
\hline Título & \multicolumn{2}{|r|}{ Informações } \\
\hline \multirow{3}{*}{$\begin{array}{l}\text { forming and } \\
\text { reforming of flocking } \\
\text { behaviors [35] }\end{array}$} & Instituição & $\begin{array}{l}\text { National Defense Academy } \\
\text { Japan }\end{array}$ \\
\hline & Local & Japão \\
\hline & Descrição & $\begin{array}{l}\text { Este trabalho propõe modificações no algoritmo clássico } \\
\text { de flocking para que as criaturas controladas possuam a } \\
\text { habilidade de seguir algumas restrições espaciais, sem } \\
\text { perder, no entanto, a complexidade baixa do algoritmo } \\
\text { que permite que o mesmo opere em tempo real. }\end{array}$ \\
\hline \multirow{3}{*}{$\begin{array}{l}\text { Roadmap-Based } \\
\text { Flocking for Complex } \\
\text { Environments }[36]\end{array}$} & Instituição & Texas A\&M University \\
\hline & Local & Estados Unidos da América \\
\hline & Descrição & $\begin{array}{l}\text { Neste trabalho é investigado o modo como a adição de } \\
\text { informações globais na forma de um mapa rodoviário do } \\
\text { ambiente permite comportamentos mais sofisticados } \\
\text { através da técnica de Flocking. }\end{array}$ \\
\hline \multirow[b]{3}{*}{$\begin{array}{l}\text { Flocking for Multi- } \\
\text { Agent Dynamic } \\
\text { Systems: } \\
\text { Algorithms and } \\
\text { Theory [37] }\end{array}$} & Instituição & California Institute of Technology \\
\hline & Local & Estados Unidos da América \\
\hline & Descrição & $\begin{array}{l}\text { Neste trabalho é apresentada uma estrutura teórica para o } \\
\text { design e análise de algoritmos distribuídos de flocking. } \\
\text { Dois casos de flocking em espaço aberto e na presença de } \\
\text { obstáculos múltiplos são considerados. São apresentados } \\
\text { três algoritmos de flocking: dois para flocking em espaço } \\
\text { aberto e um para espaços restritos. }\end{array}$ \\
\hline
\end{tabular}

\subsection{5 Árvores de Decisão}

O aprendizado através de árvores de decisão é uma alternativa para jogos nos quais predição ou classificação são necessários [3]. Esta técnica pode ser utilizada para prever uma seqüência de ações que provavelmente terá o melhor resultado na maioria das situações. Embora o aprendizado através de árvores de decisão não seja muito utilizado na elaboração de 
jogos, esta técnica é simples de se programar e entender. Um algoritmo utilizado para programar árvores de decisão é o C4.5, desenvolvido por Ross Quinlan [38].

O jogo comercial Black \& White 2 faz uso desta técnica permitindo que uma criatura seja capaz de aprender com o jogador e com outras criaturas no desenrolar do jogo [3]. As experiências armazenadas no decorrer do jogo com a criatura são organizadas no formato de uma árvore, a partir do atributo entropia, que é uma medida de desordem dos dados armazenados. Árvores de decisão possuem uma estrutura fácil de ser compreendida, são robustas a ruídos e possuem um aprendizado eficiente [10]. Na Tabela VI abaixo estão exemplos de trabalhos realizados utilizando aprendizado com árvores de decisão.

Tabela VI - Trabalhos com Árvores de Decisão

\begin{tabular}{|c|c|c|}
\hline Título & \multicolumn{2}{|r|}{ Informações } \\
\hline \multirow{3}{*}{$\begin{array}{l}\text { Learning Decision } \\
\text { Trees for Action } \\
\quad \text { Selection } \\
\text { in Soccer Agents [39] }\end{array}$} & Instituição & $\begin{array}{l}\text { University of Amsterdam Artificial Intelligence } \\
\text { Department }\end{array}$ \\
\hline & Local & Holanda \\
\hline & Descrição & $\begin{array}{l}\text { Neste trabalho são reportados os resultados da utilização } \\
\text { de aprendizado por árvores de decisão aplicados a } \\
\text { estratégias de futebol de robôs. O algoritmo foi testado } \\
\text { em um simulador. }\end{array}$ \\
\hline \multirow{3}{*}{$\begin{array}{l}\text { Competitive Learning } \\
\text { in Decision Trees [10] }\end{array}$} & Instituição & $\begin{array}{l}\text { Laboratoire d'Analyse et d'Architecture des Systèmes - } \\
\text { Centre National de la Recherche Scientifique (LAAS- } \\
\text { CNRS) }\end{array}$ \\
\hline & Local & França \\
\hline & Descrição & $\begin{array}{l}\text { Neste trabalho é apresentada uma regra de aprendizado } \\
\text { competitivo em árvores de decisão. É mostrado em } \\
\text { simulação que árvores de decisão adaptativas } \\
\text { comportam tão bem quanto outros algoritmos } \\
\text { aprendizado competitivo. }\end{array}$ \\
\hline
\end{tabular}




\subsubsection{Redes Neurais Artificiais}

Redes Neurais Artificiais (RNA) [11] são inspiradas em sistemas biológicos e possuem uma diversidade de aplicações, como tomadas de decisões, processamento de informações, otimização, predição, aprendizado e criação de filtros para entrada e saída de dados. Embora seja reconhecido por alguns autores que redes neurais ainda terão um importante papel a desempenhar nos jogos comerciais em um futuro próximo [3], os desenvolvedores de jogos apresentam relutância em aceitar o uso desta técnica no aprendizado on-line com medo de que a mesma gere comportamentos não aceitáveis para seus personagens. No entanto, RNAs vêm sendo utilizadas no aprendizado off-line de jogos, treinando os parâmetros de controle dos personagens durante a etapa de desenvolvimento do jogo.

Uma RNA pode possuir diversas arquiteturas diferentes para resolver problemas diferentes. Além disso, possui uma grande quantidade de parâmetros para serem ajustados, como, por exemplo, sua taxa de aprendizado. Como conseqüência, a RNA possui diversas possíveis aplicações, mas não é uma técnica simples de ser implementada e necessita de ajuste em seus parâmetros.

A Tabela VII abaixo mostra trabalhos realizados com Redes Neurais em jogos. O terceiro trabalho registrado nesta tabela merece destaque, pois descreve um jogo que utiliza RNAs em seu aprendizado on-line, obtendo grande sucesso (contrariando assim algumas afirmações de P. Spronck, apresentadas no capítulo 1). Tal trabalho ganhou o título de melhor artigo no CIG (IEEE Symposium on Computational Intelligence and Games) 2005. 
Tabela VII - Trabalhos realizados com Redes Neurais em Jogos

\begin{tabular}{|c|c|c|}
\hline Título & \multicolumn{2}{|r|}{ Informações } \\
\hline & Instituição & University of Cambridge \\
\hline \multirow{2}{*}{$\begin{array}{c}\text { Learning } \\
\text { Context-Dependent } \\
\text { Game Strategies [40] }\end{array}$} & Local & Inglaterra \\
\hline & Descrição & $\begin{array}{l}\text { É mostrada a implementação de uma RNA em um jogo de } \\
\text { backgammon e as melhorias trazidas pelo algoritmo nas } \\
\text { prioridades estratégicas em função do contexto do jogo. }\end{array}$ \\
\hline \multirow[b]{3}{*}{$\begin{array}{l}\text { Co-Evolving a Go- } \\
\text { Playing Neural } \\
\text { Network }[41]\end{array}$} & Instituição & $\begin{array}{l}\text { Department of Computer Science } \\
\text { Twente University Enschede }\end{array}$ \\
\hline & Local & Países Baixos \\
\hline & Descrição & $\begin{array}{l}\text { Em jogos utilizando RNAs, o treinamento das mesmas } \\
\text { ocorre geralmente medindo o desempenho em disputas } \\
\text { contra oponentes existentes. Neste trabalho é aplicada } \\
\text { uma técnica competitiva e co-evolucionária para se } \\
\text { calcular o desempenho da rede. O trabalho diz que esta } \\
\text { abordagem mostrou acelerar a evolução e resultou em } \\
\text { boas RNAs não limitadas pela qualidade de seus } \\
\text { oponentes. }\end{array}$ \\
\hline \multirow{3}{*}{$\begin{array}{c}\text { Evolving Neural } \\
\text { Network Agents in the } \\
\text { NERO Video Game } \\
{[42]}\end{array}$} & Instituição & $\begin{array}{l}\text { Department of Computer Sciences } \\
\text { University of Texas }\end{array}$ \\
\hline & Local & Estados Unidos da América \\
\hline & Descrição & $\begin{array}{l}\text { Este trabalho apresenta um método chamado rt-NEAT } \\
\text { (Real-time NeuroEvolution of Augmenting Topologies). } \\
\text { Tal método possui o objetivo de evoluir RNAs complexas } \\
\text { no aprendizado on-line de jogos. O trabalho mostra } \\
\text { experimentos realizados com o método que apresentam } \\
\text { bons resultados. }\end{array}$ \\
\hline
\end{tabular}

\subsubsection{Algoritmos Evolutivos}

Algoritmos Evolutivos (AEs) vêm sendo utilizados para evoluir estratégias de jogos desde os anos 80, como para o jogo "Iterated Prisoner's Dilemma" [43], de grande importância para economistas, cientistas sociais e cientistas da computação. O papel de se utilizar AEs em 
jogos é o de permitir que os agentes autônomos que necessitam de percepção e cognição, apresentem um grau de adaptatividade em relação às ações dos jogadores e às variações do ambiente de jogo.

Apesar de AEs, bem como as Redes Neurais, terem sido muito explorados no meio acadêmico, eles ainda apresentam resistência para serem aceitos pelos desenvolvedores de jogos, devido ao fato de que alguns pesquisadores apontam esta técnica como sendo lenta e capaz de permitir a geração de comportamentos inaceitáveis durante os jogos [3] [13]. No entanto, é reconhecido que AEs possuem o potencial para atuar em áreas nas quais técnicas tradicionais utilizadas em IA de jogos apresentam deficiências [12].

Na Tabela VIII a seguir podem ser encontradas as descrições de trabalhos já realizados com Algoritmos Evolutivos em jogos. 
Tabela VIII - Trabalhos Realizados com Algoritmos Evolutivos em Jogos

\begin{tabular}{|c|c|c|}
\hline Título & \multicolumn{2}{|r|}{ Informações } \\
\hline \multirow{3}{*}{$\begin{array}{l}\text { An Evolutionary } \\
\text { Algorithm Extended } \\
\text { by Ecological Analogy } \\
\text { and its Application to } \\
\text { the Game of Go [44] }\end{array}$} & Instituição & College of Arts and Sciences, University of Tokyo \\
\hline & Local & Japão \\
\hline & Descrição & $\begin{array}{l}\text { Neste trabalho é mostrado um } \mathrm{AE} \text { aplicado ao jogo } \\
\text { japonês de tabuleiro: } G O \text {. Duas funções criadas pelo autor } \\
\text { e inspiradas na natureza são explicadas com o objetivo de } \\
\text { melhorar o algoritmo apresentado. }\end{array}$ \\
\hline \multirow{3}{*}{$\begin{array}{c}\text { AI in Computer } \\
\text { Games: Generating } \\
\text { Interesting } \\
\text { Interactive Opponents } \\
\text { by the use of } \\
\text { Evolutionary } \\
\text { Computation [12] }\end{array}$} & Instituição & $\begin{array}{l}\text { Institute of Perception, Action and Behaviour } \\
\text { School of Informatics, University of Edinburgh }\end{array}$ \\
\hline & Local & Escócia \\
\hline & Descrição & $\begin{array}{l}\text { Neste trabalho são utilizados jogos do estilo predador- } \\
\text { presa. É proposta uma métrica de interesse para se avaliar } \\
\text { a atratividade de jogos, e esta métrica é aplicada sobre o } \\
\text { jogo produzido. Para aumentar a atratividade do jogo, é } \\
\text { utilizado um AE no aprendizado on-line do mesmo. }\end{array}$ \\
\hline \multirow{3}{*}{$\begin{array}{l}\text { Improving Adaptive } \\
\text { Game AI } \\
\text { With Evolutionary } \\
\text { Learning [6] }\end{array}$} & Instituição & $\begin{array}{l}\text { Faculty of Media \& Knowledge Engineering } \\
\text { Delft University of Technology }\end{array}$ \\
\hline & Local & Países Baixos \\
\hline & Descrição & $\begin{array}{l}\text { Neste trabalho são apresentados os resultados do uso de } \\
\text { um AE no aprendizado off-line de um jogo de estratégia } \\
\text { em tempo real. No entanto, o aprendizado on-line do jogo } \\
\text { é deixado a cargo da técnica Dynamic Scripting. }\end{array}$ \\
\hline \multirow{3}{*}{$\begin{array}{c}\text { Algoritmos } \\
\text { Evolutivos no } \\
\text { Desenvolvimento de } \\
\text { Jogos Adaptativos } \\
{[45]}\end{array}$} & Instituição & $\begin{array}{l}\text { Instituto de Ciências Matemáticas e de Computação - } \\
\text { ICMC } \\
\text { Universidade de São Paulo - USP }\end{array}$ \\
\hline & Local & Brasil \\
\hline & Descrição & $\begin{array}{l}\text { Neste trabalho é apresentado um jogo seguindo o modelo } \\
\text { predador-presa que utiliza Algoritmos Evolutivos em seu } \\
\text { aprendizado on-line. }\end{array}$ \\
\hline
\end{tabular}


Um sumário das técnicas apresentadas com suas vantagens, desvantagens e aplicações pode ser visto na Tabela IX. Observando a tabela, é possível encontrar técnicas simples, porém determinísticas, como as Máquinas de Estado Finito e os Scriptings. Tais técnicas apresentam o problema de se tornarem previsíveis pelo jogador, justificando o desenvolvimento de outras técnicas não determinísticas. A técnica de Flocking é simples e eficiente por ser específica para aplicações de movimentos de grupos; no entanto, o aprendizado on-line não é uma de suas possíveis aplicações.

Redes Neurais Artificiais foram citadas por P. Spronck como sendo inviáveis de se utilizar no aprendizado on-line de jogos, no entanto, tais afirmações já foram contrariadas no trabalho de K.O. Stanley [42]. Redes Neurais são, no entanto, de difícil implementação e para que não sejam determinísticas deve-se treinar continuamente a rede durante o jogo, para que ela aprenda com os exemplos dados por cada situação. Isso demanda muito processamento, o que conflita com a grande necessidade de recursos dos jogos.

A Lógica Nebulosa é vantajosa quando alternativas mais simples não existem. Assim sendo, antes de realizar pesquisas com esta técnica, deve-se explorar alternativas como Máquinas de Estado Finito e Scripting. Lógica Nebulosa é uma alternativa eficiente para codificar o conhecimento de especialistas, mas até hoje não foram propostos trabalhos abordando aprendizado on-line, devido a sua estrutura rígida.

Algoritmos Evolutivos e Árvores de decisão, que possuem implementação mais delicada e sensível ao ajuste de parâmetros, acabam resultando como potenciais soluções para implementação de aprendizado on-line no modelo proposto de jogo. Destas duas opções, os Algoritmos Evolutivos foram escolhidos para a realização deste trabalho pois possuem potencial para trabalhar com espaços de busca grandes, representativos de jogos de estratégia em tempo real ou Role-Playing Games [12]. O custo computacional de AEs é geralmente alto, 
pois a técnica é normalmente utilizada em problemas de otimização e tem que processar centenas de gerações até produzir uma solução aceitável. Neste trabalho, porém, o AE executa gradualmente uma geração por partida, e a perda de desempenho resultante é mínima. 
Tabela IX - Sumários das técnicas utilizadas em jogos, baseado em [3]

\begin{tabular}{|c|c|c|c|}
\hline Técnica & Vantagens & Desvantagens & Aplicações \\
\hline $\begin{array}{l}\text { Máquinas } \\
\text { de Estado } \\
\text { Finito }\end{array}$ & $\begin{array}{l}\text { - Simples } \\
\text { - Geral } \\
\text { - Usada em conjunto } \\
\text { com outras técnicas } \\
\text { - Computacionalmente } \\
\text { barata } \\
\text { - Grande capacidade de } \\
\text { codificação }\end{array}$ & $\begin{array}{l}\text { - Pode ser fracamente } \\
\text { estruturada } \\
\text { - Escalabilidade ruim } \\
\text { - Necessidade de } \\
\text { antecipar todas as } \\
\text { situações } \\
\text { - Determinística }\end{array}$ & $\begin{array}{l}\text { - Gerenciamento do } \\
\text { universo de jogo } \\
\text { - Gerenciamento de } \\
\text { objetos/personagens }\end{array}$ \\
\hline Scripting & $\begin{array}{l}\text { - Simples } \\
\text { - Pode ser utilizada por } \\
\text { não programadores } \\
\text { - Ambiente seguro }\end{array}$ & $\begin{array}{l}\text { - Necessidade de } \\
\text { antecipar todas as } \\
\text { situações } \\
\text { - Determinística }\end{array}$ & $\begin{array}{l}\text { - Gerenciar eventos } \\
\text { - IA do oponente } \\
\text { - Automatizar tarefas } \\
\text { - Árvores de conversa }\end{array}$ \\
\hline $\begin{array}{l}\text { Lógica } \\
\text { Nebulosa }\end{array}$ & $\begin{array}{l}\text { - Apresenta alternativa } \\
\text { para quando não há } \\
\text { solução simples } \\
\text { - Quando conhecimento } \\
\text { do especialista é } \\
\text { necessário } \\
\text { - Resolve problemas } \\
\text { não lineares } \\
\text { - Flexibilidade }\end{array}$ & $\begin{array}{l}\text { - Não é boa alternativa } \\
\text { quando há uma solução } \\
\text { simples } \\
\text { - Complicada de se } \\
\text { construir }\end{array}$ & $\begin{array}{l}\text { - Tomada de decisão } \\
\text { - Seleção de } \\
\text { comportamentos } \\
\text { - Filtro para } \\
\text { entrada/saída de dados } \\
\text { - Controle do estado de } \\
\text { saúde dos personagens } \\
\text { - Situação emocional dos } \\
\text { personagens }\end{array}$ \\
\hline Flocking & $\begin{array}{l}\text { - Puramente reativa } \\
\text { - Baixo requerimento } \\
\text { de memória } \\
\text { - realista }\end{array}$ & - Aplicações limitadas & $\begin{array}{l}\text { - Controle de movimento } \\
\text { de unidades } \\
\text { - Controle de grupo de } \\
\text { animais/monstros }\end{array}$ \\
\hline $\begin{array}{l}\text { Árvores de } \\
\text { Decisão }\end{array}$ & $\begin{array}{l}\text { - Robusta a ruídos } \\
\text { - Estrutura fácil de } \\
\text { compreender } \\
\text { - Algoritmo de } \\
\text { treinamento/avaliação } \\
\text { eficiente }\end{array}$ & $\begin{array}{l}\text { - Necessário ajuste de } \\
\text { parâmetros }\end{array}$ & $\begin{array}{l}\text { - Predição } \\
\text { - Classificação } \\
\text { - Aprendizado }\end{array}$ \\
\hline $\begin{array}{l}\text { Redes } \\
\text { Neurais }\end{array}$ & $\begin{array}{l}\text { - Flexível } \\
\text { - Não determinística } \\
\text { - Não linear }\end{array}$ & $\begin{array}{l}\text { - Necessário ajuste de } \\
\text { parâmetros } \\
\text { - Difícil escolha de } \\
\text { variáveis } \\
\text { - Técnica complicada } \\
\text { - Exige muitos recursos } \\
\text { computacionais }\end{array}$ & $\begin{array}{l}\text { - Memória } \\
\text { - Reconhecimento de } \\
\text { padrões } \\
\text { - Predição } \\
\text { - Classificação } \\
\text { - Controle de } \\
\text { comportamento }\end{array}$ \\
\hline $\begin{array}{l}\text { Algoritmos } \\
\text { Evolutivos }\end{array}$ & $\begin{array}{l}\text { - Método de busca } \\
\text { robusto } \\
\text { - Efetivo em espaços de } \\
\text { busca grandes, } \\
\text { complexos e pouco } \\
\text { compreendidos } \\
\text { - Não linear } \\
\text { - Não determinístico }\end{array}$ & $\begin{array}{l}\text { - Uso intensivo de } \\
\text { recursos do computador } \\
\text { - Necessário ajuste de } \\
\text { parâmetros }\end{array}$ & $\begin{array}{l}\text { - Otimização } \\
\text { - Aprendizado } \\
\text { - Desenvolvimento de } \\
\text { estratégias para jogos } \\
\text { - Evolução de } \\
\text { comportamento } \\
\text { - Encontrar caminhos a } \\
\text { serem percorridos }\end{array}$ \\
\hline
\end{tabular}




\subsection{COMPUTAÇÃO EVOLUTIVA}

A Computação Evolutiva (CE) compreende uma família de algoritmos inspirados na Teoria da Evolução Natural das Espécies de Charles Darwin [46]. Os algoritmos pertencentes a este campo da computação são chamados de Algoritmos Evolutivos (AEs). Introduzidos por John Holland [47], Algoritmos Genéticos são considerados como uma área da Computação Evolutiva, juntamente com programação genética [48], hardware evolutivo [49] SAGA [50], entre outros.

Um AE pode ser explicado como sendo um procedimento iterativo. No começo de sua execução, é gerada uma população de indivíduos geralmente aleatória. Cada um destes indivíduos possui um "cromossomo" que representa uma solução candidata para o problema em questão, e cada solução passa por uma função de avaliação, recebendo um valor de aptidão (fitness score) que indica a eficácia da solução [51]. Com base nesta pontuação, um grupo de indivíduos é selecionado. Uma variedade de métodos de seleção é encontrada na literatura, como, por exemplo, o da Roleta e o do Elitismo [52]. Após a etapa de seleção são aplicados os operadores evolutivos de crossover e mutação, criando assim um novo conjunto de soluções candidatas (uma nova geração). Desta forma, o processo é reiniciado a partir da fase de avaliação.

Com o passar das gerações do AE, existe uma tendência de que as soluções obtidas sejam cada vez mais adequadas [53]. Além disso, caso o problema no qual o AE está operando seja mudado durante o processo evolutivo, é esperado que este comece a buscar dinamicamente novas soluções, gerando assim soluções adaptativas [54]. Na Figura 2, a seguir, é apresentada a estrutura padrão de um AE. 


\section{Inicie a População.}

2 Repita enquanto critério de parada não for satisfeito:

3 Calcule a aptidão de cada possível solução (cromossomo).

4 Selecione cromossomos para a reprodução.

5 Gere novos cromossomos utilizando operadores evolutivos.

6 Componha a nova população.

\section{Figura 2 - Estrutura básica de um AE}

Na primeira etapa, a população é gerada com soluções aleatórias, ou utilizando outras abordagens [52]. O segundo passo se refere a um critério de parada do algoritmo. Este critério pode ser a aptidão da melhor solução encontrada (quando a solução for suficientemente boa, o algoritmo pára) ou o número máximo de gerações utilizadas (normalmente quando existem restrições de tempo para o algoritmo). Alternativamente, pode haver aplicações que exijam constante adaptação da solução ao ambiente de trabalho e, neste caso, o algoritmo é executado constantemente e só para quando a aplicação termina. Este é o caso, por exemplo, do aprendizado on-line em jogos, no qual o algoritmo pode funcionar até o jogo ser desligado.

No passo três, é calculada a aptidão dos indivíduos. O cálculo desta aptidão pode ser feito de forma direta (utilizando uma função matemática disponível) ou também pode ser realizado de forma indireta. Um exemplo de cálculo da aptidão de forma direta pode ser encontrado ao se utilizar um AE para evoluir um "navegador" de um robô móvel, no qual a aptidão pode ser calculada pela distância percorrida pelo robô (maior distância, maior aptidão) e pelo número de colisões do robô com o ambiente (quanto mais colisões, menor a aptidão). 
O quarto passo se refere à seleção de alguns cromossomos para a reprodução. Para tanto, são encontrados vários métodos na literatura, como o da roleta [52], o do torneio [52], o do elitismo [51] ou o de hereditariedade [55]. Outro método possível é utilizar a seleção do cromossomo com melhor aptidão para ser o pai da população na próxima iteração [56], ou seja, o cromossomo "pai” é mantido para a próxima geração, e os operadores evolutivos utilizados são aplicados aos outros cromossomos, criando uma nova geração de soluções candidatas durante o quinto passo. Vários operadores evolutivos podem ser utilizados no AE, como, por exemplo, a técnica de genocídio [56] e funções de predação [57] [58], que simulam um predador que elimina os indivíduos menos adaptados da população. Os operadores evolutivos mais conhecidos são os de crossover e o de mutação. Na Figura 3 abaixo, pode ser visto um exemplo de crossover, no qual o cromossomo filho tem para cada bit uma chance de $50 \%$ de receber o bit correspondente de cada um dos outros dois cromossomos selecionados para sua geração. Um exemplo de mutação pode ser visto na Figura 4. Neste exemplo, cada bit pertencente ao cromossomo possui uma pequena chance de ser modificado. No exemplo apresentado na figura, o quarto bit sofreu uma mutação, mudando seu valor de 0 para 1.

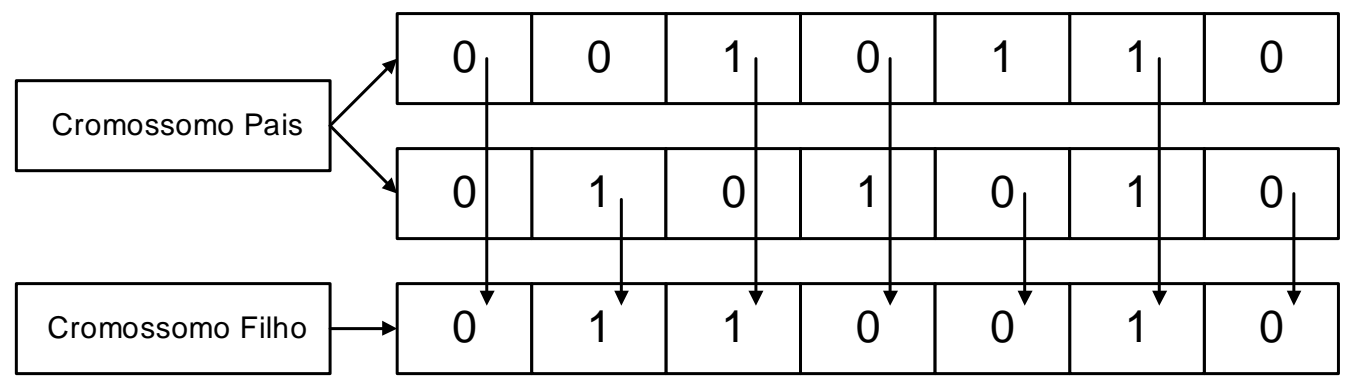

Figura 3- Exemplo de Crossover 


\begin{tabular}{|c|c|c|c|c|c|c|c|}
\hline Cromossomo Inicial & 0 & 0 & 1 & 0 & 1 & 1 & 0 \\
\hline & \multicolumn{7}{|c|}{$\begin{array}{l}\text { Mutaçăo } \\
\end{array}$} \\
\hline Cromossomo Mutado & 0 & 0 & 1 & 1 & 1 & 1 & 0 \\
\hline
\end{tabular}

Figura 4 - Um Exemplo de Mutação 


\section{AMBIENTE DE APRENDIZADO ON-LINE EM JOGOS ELETRÔNICOS}

A sigla CRPGs é comumente utilizada para se referir a jogos de RPG para computador (Computer Role-Playing Games). Nessa categoria de jogo eletrônico, o jogador controla um simples personagem, ou um grupo de personagens, em um mundo virtual. Tais jogos se originaram do RPG (Role-Playing Game) de mesa ${ }^{6}$, que tiveram início na década de 70.

Os primeiros RPGs eletrônicos foram criados também na década de 70 , os chamados “Multi-User Dungeon, Domain or Dimension", conhecidos popularmente como MUDs. Não possuem interface gráfica, e a interação do jogador é obtida através de comandos textuais, baseados em alguma língua natural (como o inglês). Alguns exemplos de MUDs são: dikuMud [59], AberMUD [60] e Armageddon MUD [61].

Nos últimos 20 anos uma grande quantidade de RPGs eletrônicos com interfaces gráficas foi produzida [22]. Como exemplos de jogos comerciais bem sucedidos, podem ser citados: o Final Fantasy $^{7}$, o Neverwinter Nights ${ }^{8}$ e o Baldur's Gate ${ }^{9}$. Em 2006, uma pesquisa realizada pelo NPD Group [1] revelou que os jogos de RPG vendidos corresponderam a 12,4\% do total

\footnotetext{
${ }^{6}$ Wizards of the Coast, Dungeons \& Dragons, http://www.playdnd.com , último acesso: 24/01/2007

${ }^{7}$ SQUARE-ENIX. Final Fantasy Series. Disponível em: <http://www.square-enix.com/na/title/ff/>. Acesso em: 22 fev. 2007.

${ }^{8}$ BIOWARE. Neverwinter Nights. Disponível em: <http://nwn.bioware.com/>. Acesso em: 22 fev. 2007.

${ }^{9}$ BIOWARE. Baldur's Gate. Disponível em: <http://www.bioware.com/games/baldurs_gate/>. Acesso em: 22 fev. 2007.
} 
de jogos vendidos para computador, vencendo os gêneros de Aventura (5,8\%), Ação (4,7\%) e Esportes $(3,7 \%)$.

O jogo montado para este projeto é baseado no sistema de batalha do jogo Baldur's Gate. Tal escolha deve-se ao fato de que o simulador montado por P. Spronck foi também baseado neste jogo, facilitando a comparação dos resultados. O nível de complexidade em Baldur's Gate é bem alto quando comparado a outros jogos [22]. Muitas vezes são necessárias 100 horas de jogo para se chegar até o final da história. Este estilo de jogo envolve a interação do personagem controlado pelo jogador em um mundo virtual, envolvendo a resolução de quebra cabeças e de combates que, como nos outros jogos de RPG, são baseados principalmente em estratégias complexas, contrárias à maioria dos outros gêneros, que exigem principalmente bons reflexos do jogador [13].

Uma subdivisão dos CRPGs que vêm ganhando força nos últimos anos são os chamados "Massive Multiplayer Online Role-Playing Games", conhecidos como MMORPGs. Estes jogos permitem que milhares de jogadores interajam simultaneamente em um mundo virtual através da Internet. Como exemplos destes jogos podem ser citados o World of Warcraft ${ }^{10}$, o Ragnarok Online ${ }^{11}$, o Ultima Online ${ }^{12}$ e o Erinia $^{13}$, produzido no Brasil. Pesquisadores apontam o desenvolvimento de comportamentos individuais e a elaboração de estratégias de

${ }^{10}$ BLIZZARD. World of Warcraft. Disponível em: <http://www.worldofwarcraft.com/index.xml>. Acesso em: 12 fev. 2008.

${ }^{11}$ GRAVITY. Ragnarok Online. Disponível em: <http://iro.ragnarokonline.com/>. Acesso em: 12 fev. 2008.

${ }^{12}$ ORIGIN. Ultima Online. Disponível em: <http://www.uoherald.com/news/>. Acesso em: 12 fev. 2008.

${ }^{13}$ IGNIS GAMES. Erinia. Disponível em: < http://www.erinia.com.br/>. Acesso em: 12 fev. 2008. 
oponentes em CRPGs como boas direções a serem seguidas nas pesquisas de IA para Jogos [22].

\subsection{O JOGO PROPOSTO}

O jogo implementado segue o modelo do simulador elaborado para realização dos experimentos de P. Spronck [13]. Neste jogo, o jogador é responsável pela estratégia de quatro personagens, contra quatro personagens controlados pelo computador. O jogo é um simulador das batalhas que ocorrem em jogos de RPG do estilo Baldur's Gate. Este estilo de jogo utiliza os sistemas mais complexos encontrados em RPGs eletrônicos. A Figura 5 mostra um quadro do jogo desenvolvido para este trabalho ${ }^{14}$.

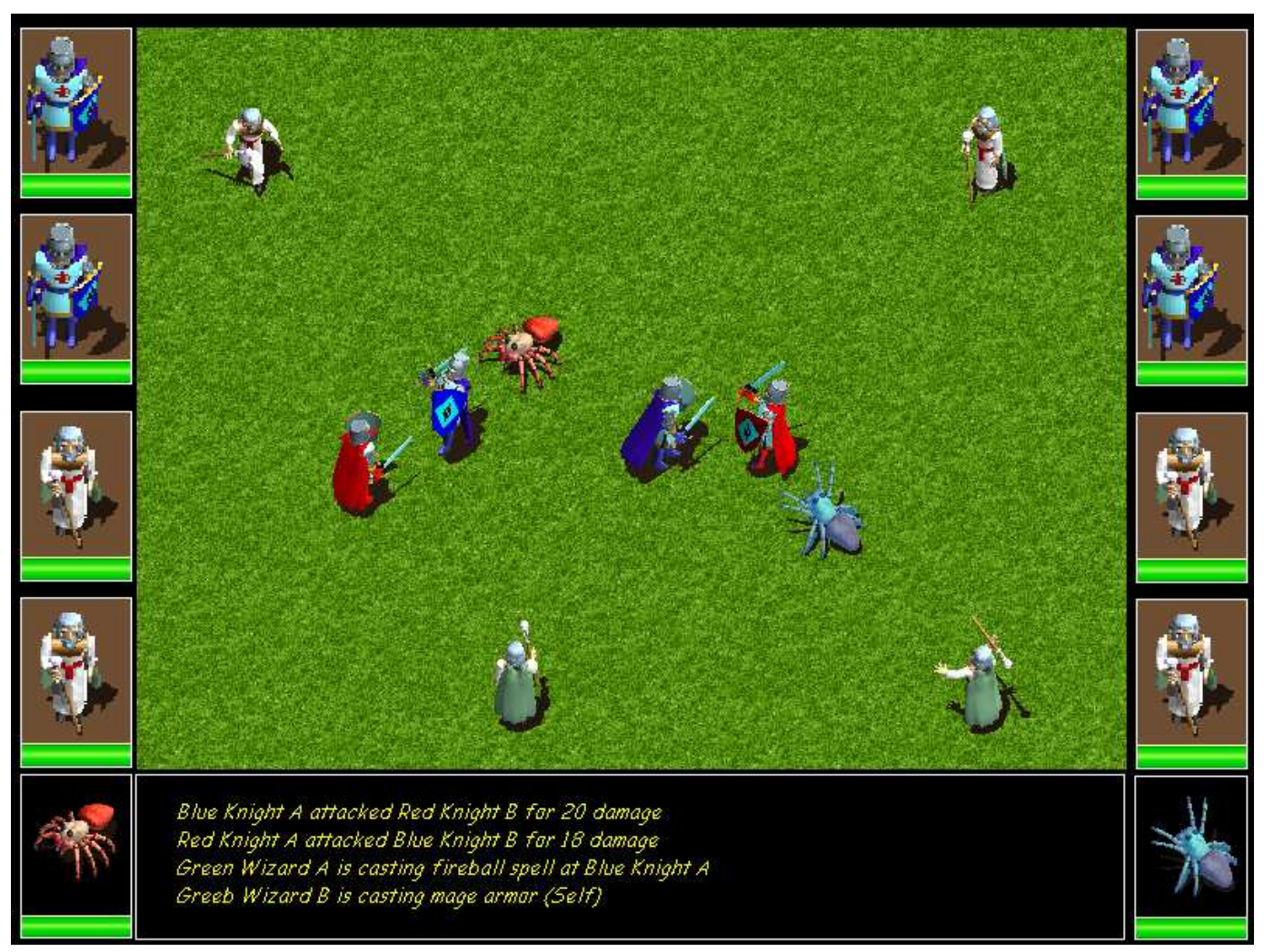

Figura 5 - Cenário do jogo proposto

\footnotetext{
${ }^{14}$ Sprites utilizados no jogo extraídos de <http://reinerstileset.4players.de/>. Acesso em: 19 fev. 2008.
} 
O jogo ocorre com o encontro de dois grupos de personagens, no qual cada um dos grupos (um controlado pelo computador e outro pelo jogador) é composto por dois personagens magos e dois guerreiros. O equipamento dos personagens é estático, cada personagem possui duas poções mágicas dentre as três possíveis, e cada mago possui sete magias de um total de 21 possíveis. As magias existentes são de variados tipos, entre eles:

- Dano: reduzem os pontos de vida dos oponentes;

- Bênção: aumentam atributos dos personagens, como, por exemplo, a força;

- Maldições: atribuem efeitos negativos nos oponentes, como, por exemplo, reduzir um atributo, ou deixar o personagem paralisado por um determinado número de turnos;

- Controle: tentam controlar os oponentes, fazendo com que os mesmos lutem durante alguns turnos do lado contrário da batalha;

- Efeito de Área: como qualquer outra magia, mas tem efeito em um grupo de personagens dentro de uma determinada área do jogo;

- Invocação: um novo personagem aparece para lutar ao lado do mago invocador, durante um certo número de turnos.

Cada um dos personagens possui as ações que serão tomadas representadas por scripts compostos por cinco regras para um guerreiro (selecionadas de uma base contendo 20 regras) e 10 regras para um mago (selecionadas de uma base de 50 regras). A Tabela $\mathrm{X}$ abaixo mostra um exemplo de um script de guerreiro, no qual cada linha representa uma regra. 


\begin{tabular}{|c|l|l|l|}
\hline Regra & \multicolumn{1}{|c|}{ Ação } & \multicolumn{1}{|c|}{ Alvo } & \multicolumn{1}{|c|}{ Condiçães } \\
\hline $\mathbf{1}$ & Beber Poção de Cura & Próprio personagem & Pontos de vida < 50\% e personagem \\
possuir poção
\end{tabular}


Quanto mais acima na tabela, maior a prioridade da regra: a cada turno, o guerreiro controlado pelo script daTabela $\mathrm{X}$ testa as condições de sua primeira regra. Caso elas sejam satisfeitas, a ação da regra é executada; caso contrário, são testadas as condições da próxima regra. Tal procedimento se repete até que alguma ação seja executada; no caso de nenhuma ação poder ser executada, a ação de "passar o turno" entra em execução (isso significa que o personagem abre mão de seu movimento). A Figura 6 mostra o fluxograma responsável pelo controle do personagem que possui o script da Tabela X.

As regras que compõem os scripts são formadas a partir de cinco ações básicas: atacar, beber uma poção, se mover, executar uma magia ou passar a vez. O conjunto contendo quatro scripts (dois para magos e dois para guerreiros) constitui uma estratégia a ser usada por um time. O jogo funciona da seguinte forma: dois times são colocados no mesmo ambiente e entram em combate utilizando, cada um, sua respectiva estratégia. Quando um time ficar sem personagens vivos (todos os personagens possuírem pontos de vida igual a 0), este é considerado derrotado, e, conseqüentemente, o outro time é o vencedor. Se o time do jogador vencer o time controlado pelo computador, um novo time é criado para dar continuidade ao jogo, resultando em uma próxima batalha. Antes que a nova batalha se inicie é apresentada ao jogador a possibilidade de mudar a estratégia de seu time. 


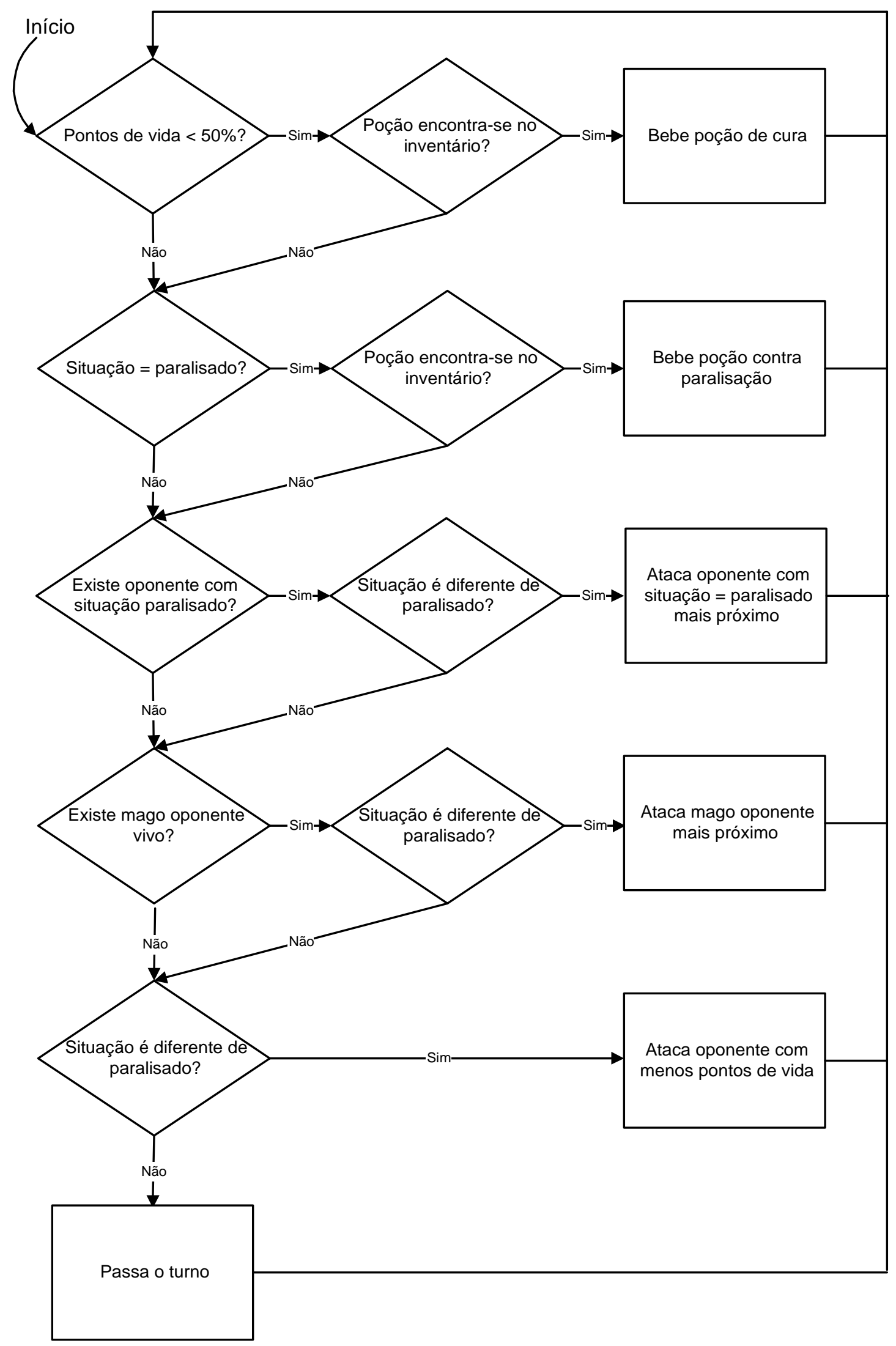

Figura 6 - Fluxograma de controle do personagem que possui o script da Tabela $\mathrm{X}$ 


\subsection{OS ALGORITMOS}

Foram implementados dois algoritmos responsáveis por elaborar as estratégias a serem adotadas pelo computador: Dynamic Scripting e um AE. Os mesmos são explicados nas subseções a seguir.

\subsubsection{Dynamic Scripting}

Dynamic Scripting (DS) é uma técnica de aprendizado não supervisionado proposta por P. Spronck e Postma [13] para permitir o aprendizado on-line em jogos comerciais. Segundo os criadores da técnica, a mesma satisfaz os quatro requisitos para um aprendizado on-line funcionar na prática: rapidez, efetividade, robustez e eficiência.

A técnica mantém bases de regras, uma para cada oponente controlado pelo computador. Antes da batalha se iniciar, estas regras são usadas para criar scripts que controlem os comportamentos dos personagens. A probabilidade de que uma regra seja utilizada para montar um script para o personagem é dada por um peso relativo à mesma regra. A adaptação ocorre modificando os pesos associados às regras da base, baseando-se na taxa de sucesso ou falha de quando a regra é utilizada: se o computador vencer a batalha, as regras usadas têm seu peso aumentado, se a batalha for perdida, o peso das regras utilizadas é reduzido. $\mathrm{O}$ mecanismo de aprendizado utilizado é baseado em técnicas de aprendizado por reforço. A Figura 7 abaixo ilustra o funcionamento da técnica. 


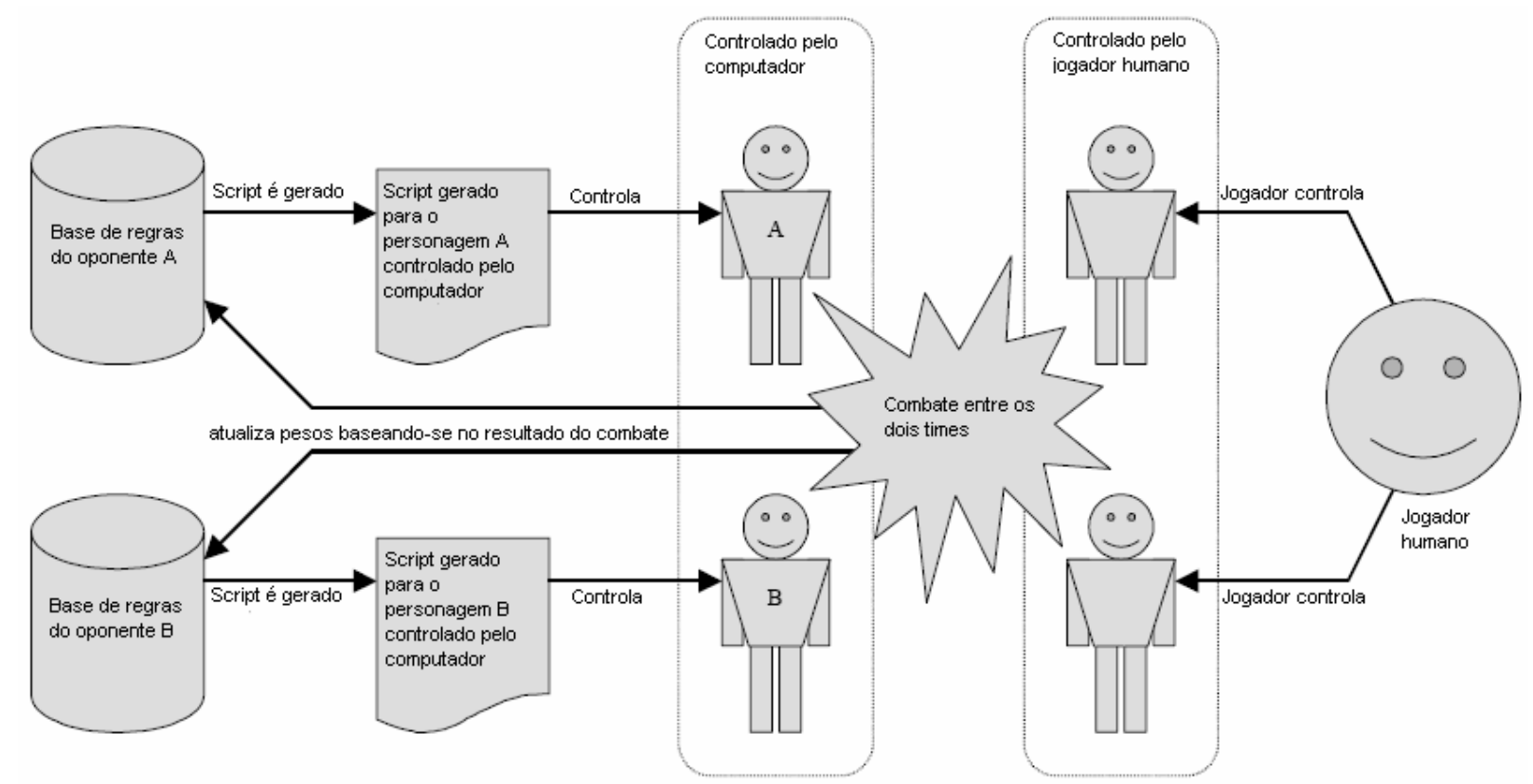

Figura 7 - O processo do DS (extraído e traduzido de [13])

Após selecionadas as regras para a composição do script a ser utilizado, as mesmas são ordenadas segundo um algoritmo de prioridade. A função de atualização dos pesos é baseada em duas funções de aptidão, sendo uma função que avalia o sucesso do grupo como um todo, e outra para cada indivíduo:

- Aptidão do grupo: possui um valor real no intervalo [0,1], que é 0 se o grupo perdeu a luta e 0,5 mais a metade da média da percentagem de saúde restante dos personagens do time. Esta função de aptidão encontra-se representada na Equação 1 abaixo.

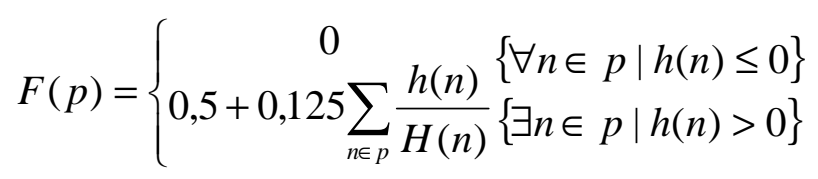


Sendo:

$\mathbf{F}(\mathbf{p})$ : Função de aptidão do grupo $p$

$\mathbf{H}(\mathbf{n})$ : Saúde total do personagem $n$

$\mathbf{h}(\mathbf{n})$ : saúde restante do personagem $n$ após a batalha (número natural entre 0 e H(n))

- Aptidão de um personagem: valor real no intervalo [0,1], baseado em quatro fatores:

(1) a média da vida restante do grupo, (2) o dano médio causado ao grupo oponente,

(3) a saúde restante do personagem sendo avaliado (ou, se o personagem morreu, o instante de sua morte) e (4) o valor de aptidão do grupo. A função que avalia a aptidão de um personagem é dada pela Equação 2 abaixo:

$$
F(p, c)=0,05 \sum_{n}\left\{\begin{array}{cl}
0 & \{n \in p \wedge h(n) \leq 0\} \\
0,5+0,5 \frac{h(n)}{H(n)} & \{n \in p \wedge h(n)>0\} \\
1 & \{n \notin p \wedge h(n) \leq 0\} \\
0,5-0,5 \frac{h(n)}{H(n)} & \{n \notin p \wedge h(n)>0\}
\end{array}\right\}\left\{\begin{array}{cl}
\frac{\min (d c(c), 100)}{1000} & \{h(c) \leq 0\} \\
0,2+0,1 \frac{h(c)}{H(c)} & \{h(c)>0\}
\end{array}+0,3 F(p)\right.
$$

Equação 2

Sendo:

$\mathbf{F}(\mathbf{p}, \mathbf{c})$ : Aptidão de um personagem c pertencente ao grupo $\mathrm{p}$

n: qualquer personagem do encontro (controlado pelo computador ou pelo jogador)

dc(c): contador de tempo até a morte do personagem c

A partir desta função, a aptidão do personagem recebe uma grande recompensa caso o grupo ganhe (o personagem sobrevivendo ou não); uma recompensa menor para o caso do indivíduo sobreviver; e, por último, uma recompensa ainda menor baseada na sobrevivência 
de seus companheiros e no dano causado ao grupo oponente (sendo estas três recompensas cumulativas).

Com base na última função de aptidão, uma função de adaptação dos pesos é aplicada na base de regras. Apenas as regras utilizadas nos scripts que participaram da batalha têm seus pesos atualizados. A função de atualização dos pesos é definida na Equação 3 abaixo:

$$
\text { Wnovo }=\left\{\begin{array}{cc}
\max \left(0, W-M P \frac{b-F(p, c)}{b}\right) & \{F(p, c)<b\} \\
\min \left(W+M P \frac{F(p, c)-b}{1-b}, M W\right) & \{F(p, c) \geq b\}
\end{array}\right.
$$

Equação 3

Sendo:

\author{
Wnovo : Novo peso sendo calculado \\ W : Peso antigo \\ MP : Valor máximo de penalidade (30) \\ MR : Valor máximo de recompensa (100) \\ MW : Valor máximo do peso (2000) \\ b : Ponto de equilíbrio $(0,3)$
}

Quando a aptidão do personagem é igual ao ponto de equilíbrio, são mantidos os pesos das regras utilizadas para formação de seu script. Para manter a soma de todos os pesos constante na base de regras, a mudança dos pesos é executada através de uma redistribuição de todos os pesos na mesma base de regras. No início, todos os pesos possuem o valor 100 . 
Terminado o processo de adaptação de pesos, é fechado um ciclo do algoritmo (como indicado pela Figura 7) e as novas bases de regras são utilizadas para a formação dos scripts a serem utilizados na próxima batalha.

\subsubsection{O Algoritmo Evolutivo Implementado}

O AE proposto possui como cromossomos as estratégias de comando de um time composto por quatro personagens: dois guerreiros e dois magos (um conjunto de quatro scripts). Cada regra que compõe estes scripts é considerada um parâmetro do cromossomo sendo avaliado, resultando em um total de 30 regras por cromossomo: 5 para cada guerreiro e 10 para cada mago. $\mathrm{O}$ cromossomo descrito pode ser visto na Figura 8.

Script Guerreiro 1
\begin{tabular}{|c|c|c|c|c|c|c|c|c|c|c|c|}
\hline Regra & & Regra & Regra & & Regra & Regra & & Regra & Regra & Regra \\
$\mathbf{1}$ & $\ldots$ & $\mathbf{5}$ & $\mathbf{1}$ & $\ldots$ & $\mathbf{5}$ & $\mathbf{1}$ & $\ldots$ & $\mathbf{1 0}$ & $\mathbf{1}$ & $\mathbf{. .}$ & $\mathbf{1 0}$ \\
\hline
\end{tabular}

Figura 8 - O cromossomo proposto

A população evoluída é composta por quatro cromossomos. O funcionamento do $\mathrm{AE}$ proposto constitui de três etapas básicas: geração da população inicial, teste dos indivíduos no ambiente e geração de uma nova população. A Figura 9 abaixo ilustra o funcionamento do algoritmo. 


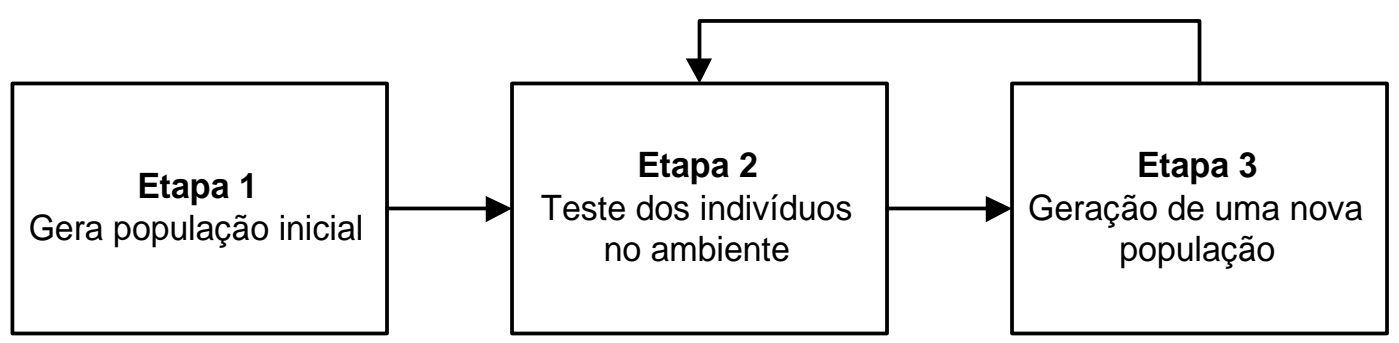

Figura 9 - Funcionamento do AE

Etapa 1 - Geração da população inicial: Nessa etapa é gerada a população inicial contendo quatro cromossomos. Para cada um dos quatro membros da população, são geradas oito estratégias de jogo selecionando-se de forma aleatória as regras para os scripts. É realizado um torneio entre estas estratégias, como ilustra a Figura 10, e a estratégia vencedora é o cromossomo inicial do correspondente membro da população. Os confrontos realizados entre estas estratégias ocorrem colocando as duas para combater no ambiente de jogo em background, ou seja, este confronto não é visto pelo usuário do jogo. São realizados quatro torneios como o mostrado pela Figura $10 \mathrm{com}$ a finalidade de gerar os quatro indivíduos da população inicial. Esta Etapa não compromete o desempenho do jogo, pois ocorre antes das partidas com o usuário começarem.

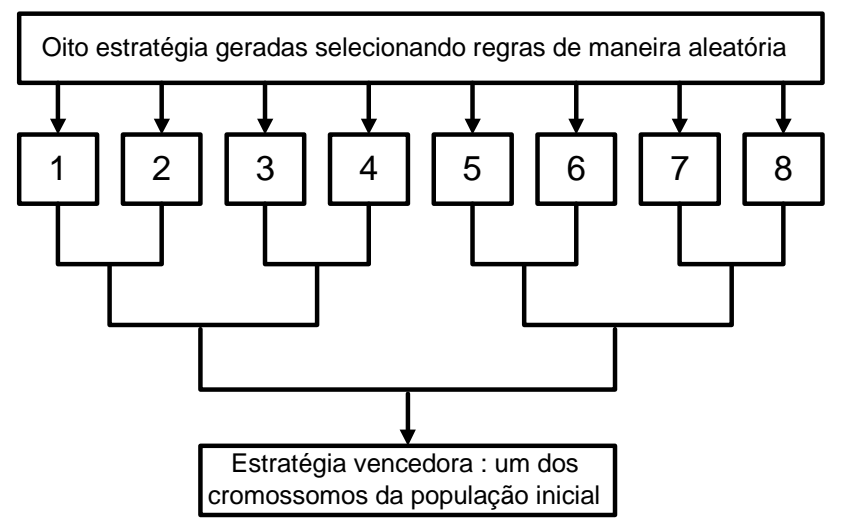

Figura 10 - Torneio realizado para seleção dos valores iniciais de um cromossomo 
Etapa 2 - Teste dos indivíduos no ambiente: Nesta etapa, ocorre o confronto entre a estratégia da população sendo evoluída com a estratégia do jogador. Os seguintes procedimentos são realizados:

1. O valor aptidão de cada cromossomo é iniciado como -1 , significando que os cromossomos ainda não possuem um valor de aptidão. É selecionado o primeiro cromossomo da população.

2. Os scripts que compõem o cromossomo são utilizados para controlar o grupo de personagens do computador.

3. Ocorre uma batalha entre os personagens do computador e os personagens do jogador. Após o término da batalha, calcula-se uma pontuação para a estratégia utilizada pelo computador, dada pela função de aptidão do grupo: Fit(p), representada pela Equação 4 a seguir.

$$
\operatorname{Fit}(p)=\left\{\begin{array}{l}
0,5-0,125 \sum_{m \in o} \frac{h(m)}{H(m)}\{\forall n \in p \mid h(n) \leq 0\} \\
0,5+0,125 \sum_{n \in p} \frac{h(n)}{H(n)}\{\exists n \in p \mid h(n)>0\}
\end{array}\right.
$$

Equação 4

\section{Sendo:}

Fit(p): Função de aptidão do grupo $p$

H(n): Saúde total do personagem $n$

h(n): saúde restante do personagem $n$ após a batalha (número natural entre 0 e H(n))

o: grupo oponente ao grupo $\mathrm{p}$ 
4. Caso a estratégia do computador tenha sido vitoriosa, a mesma estratégia é mantida para a próxima batalha (Retorna para procedimento 3).

5. Caso o computador tenha sido derrotado pelo jogador, o indivíduo com o cromossomo responsável pela estratégia utilizada recebe um valor de aptidão (fitness) igual à média aritmética das pontuações obtidas por sua estratégia no procedimento dois, dada pela Equação 5 abaixo.

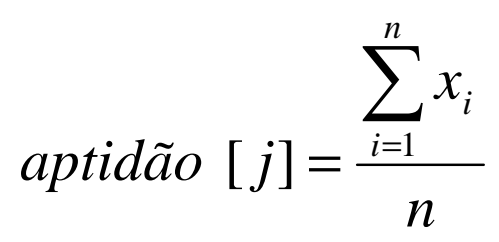

Equação 5

Sendo:

j: cromossomo sendo avaliado

aptidão[j] : valor de aptidão do cromossomo j

n: número de vitórias +1 (número de batalhas utilizando a estratégia de j)

$\mathbf{x}_{\mathbf{i}}$ : pontuação obtida na i-ésima batalha dada pela Equação 4

6. Se ainda houver um cromossomo na população sem um valor de aptidão (aptidão = 1), então retorna para o procedimento 2, testando o cromossomo em questão. Caso contrário, a etapa dois chega ao fim. 
Etapa 3 - Geração de uma nova população: Após todos os indivíduos terem sido avaliados, esta etapa entra em execução com o objetivo de aproveitar as estratégias que obtiveram maior sucesso para gerar uma nova população da qual é esperado um maior potencial para superar a estratégia utilizada pelo jogador. Para se gerar a nova população, é selecionado o melhor indivíduo da população atual, isto é, o indivíduo com maior valor de aptidão (chamado de “pai” da população). Após o pai da população ter sido selecionado, os operadores evolutivos de crossover e mutação são responsáveis por determinar três cromossomos da nova população; o quarto cromossomo é exatamente igual ao cromossomo do indivíduo "pai". Os operadores evolutivos implementados de crossover e mutação são explicados abaixo:

- Crossover: dos quatro cromossomos que irão compor a nova população, um é uma cópia do cromossomo pai. Para cada um dos outros três cromossomos é realizado o crossover de seus genes com os genes do cromossomo "pai”. Cada parâmetro do novo cromossomo apresenta $50 \%$ de chance de receber o valor do cromossomo do "pai" e $50 \%$ de chance de receber o valor do cromossomo associado. A Figura 11 mostra um exemplo de crossover, no qual cada regra é representada por um número inteiro.

\begin{tabular}{|c|c|c|c|c|c|c|c|c|c|c|c|c|}
\hline $\begin{array}{l}\text { Cromossomo } \\
\text { associado }\end{array}$ & 1 & $\cdots$ & 7 & 8 & $\cdots$ & 12 & 5 & $\cdots$ & 17 & 4 & $\cdots$ & 9 \\
\hline Cromossomo "pai" & 2 & $\cdots$ & 9 & 12 & $\cdots$ & 3 & 9 & $\cdots$ & 11 & 7 & $\cdots$ & 2 \\
\hline $\begin{array}{c}\text { Cromossomo } \\
\text { resultante }\end{array}$ & $1^{\downarrow}$ & $\cdots$ & $9^{\downarrow}$ & $12^{\downarrow}$ & $\cdots$ & 12 & $5^{\downarrow}$ & $\cdots$ & $17^{\downarrow}$ & 7 & $\ldots$ & $9 \downarrow$ \\
\hline
\end{tabular}

Figura 11 - Exemplo do crossover proposto

Em um mesmo script não pode haver regras repetidas, portanto se ao final do processo explicado forem detectadas regras repetidas no script de um mesmo personagem, uma das regras é substituída pela outra possível regra daquela posição (retirando a regra do outro 
cromossomo gerador). No exemplo da Figura 11, o segundo script apresenta duas regras iguais (com valor 12). Uma das duas regras é então selecionada aleatoriamente (por exemplo a regra mais a esquerda) e tem seu valor substituído pela outra regra disponível para aquela posição (a regra de número 8 do cromossomo associado). A Figura 12 abaixo ilustra o cromossomo resultante para esta situação.

\begin{tabular}{|c|c|c|c|c|c|c|c|c|c|c|c|c|}
\hline $\begin{array}{l}\text { Cromossomo } \\
\text { associado }\end{array}$ & 1 & $\cdots$ & 7 & 8 & $\cdots$ & 12 & 5 & $\cdots$ & 17 & 4 & $\cdots$ & 9 \\
\hline Cromossomo "pai" & 2 & $\ldots$ & 9 & 12 & $\ldots$ & 3 & 9 & $\ldots$ & 11 & 7 & $\cdots$ & 2 \\
\hline $\begin{array}{c}\text { Cromossomo } \\
\text { resultante }\end{array}$ & 1 & $\cdots$ & 9 & $8^{\downarrow}$ & $\cdots$ & 12 & 5 & $\cdots$ & 17 & 7 & $\cdots$ & 9 \\
\hline
\end{tabular}

Figura 12 - Caso específico de crossover: a primeira regra do segundo script recebe o parâmetro do cromossomo associado para não possuir regras repetidas

No caso da regra 8 ainda fazer parte do script (ou seja, alguma das outras regras do script também seja a número 8), então uma regra não pertencente ao script é selecionada aleatoriamente, substituindo a regra anterior.

- Mutação: após realizado o crossover, cada parâmetro do cromossomo resultante possui 5\% de chance de ser substituído por uma regra aleatória que não pertença ao script em questão. A Figura 13 ilustra um exemplo da função de mutação proposta. É importante ressaltar que o cromossomo da nova população, contendo valores iguais ao do cromossomo pai da geração anterior, não passa pelas etapas de crossover e nem de mutação. 


\begin{tabular}{|c|c|c|c|c|c|c|c|c|c|c|c|c|}
\hline $\begin{array}{l}\text { Cromossomo } \\
\text { original (resultante } \\
\text { do crossover) }\end{array}$ & 1 & $\ldots$ & 9 & 8 & $\ldots$ & 12 & 5 & $\ldots$ & 17 & 7 & $\ldots$ & 9 \\
\hline $\begin{array}{l}\text { Cromossomo } \\
\text { resultante da } \\
\text { mutação }\end{array}$ & 1 & $\ldots$ & 9 & $3^{\downarrow}$ & $\ldots$ & 12 & 5 & $\ldots$ & 17 & 7 & $\ldots$ & 9 \\
\hline
\end{tabular}

Figura 13 - Exemplo da mutação proposta

Novamente, se ao final do processo de mutação são detectadas regras repetidas no script de um mesmo personagem, as regras repetidas são substituídas por outras aleatórias até que não se encontre nenhuma regra repetida. Após a nova população ter sido gerada, a mesma é avaliada chamando novamente a etapa dois. Este laço entre as etapas dois e três (Figura 9) representam a capacidade de adaptação do algoritmo durante todo o jogo. O laço só termina no momento em que o jogo é encerrado pelo jogador.

É interessante observar que o AE apresentado utiliza um cromossomo e uma função de aptidão que evolui a estratégia do time de personagens, desta forma o algoritmo busca obter um comportamento otimizado para o grupo, e não para os personagens individualmente. É esperado por este motivo, que as estratégias encontradas pelo algoritmo apresentem cooperação entre os personagens. Tal característica é interessante de ser encontrada no algoritmo já que no jogo construído o que define a vitória do jogador ou da máquina é o comportamento do grupo de personagens. Esta constatação inclui o trabalho dentro da área de Sistemas Multi-Agentes [62], que possui como objeto de estudo a coletividade, e não um único indivíduo. 


\subsection{O ESPAÇO DE BUSCA}

O espaço de busca onde os dois algoritmos de aprendizado (AE e DS) estão envolvidos é dado pelo tamanho do script responsável por controlar o grupo de personagens. O script contém um total de 30 regras para controlar os quatro personagens do time, como explicado em 3.1. Destas 30 regras, dez pertencem ao primeiro mago do time, dez ao segundo, cinco ao primeiro guerreiro e cinco ao segundo. As regras do mago são selecionadas em uma base contendo 50 regras possíveis, as regras dos guerreiros são selecionadas de uma segunda base contendo 20 regras. Como as regras são ordenadas segundo um algoritmo de prioridade, o que importa é quais são as regras selecionadas, e não a ordem das mesmas. Segundo estas considerações, o espaço de busca é dado por:

$$
C(50,10) * C(50,10) * C(20,5) * C(20,5)
$$

sendo:

$\mathbf{C}(\mathbf{n}, \mathbf{k}) \quad$ a combinação simples de $\mathbf{n}$ elementos tomados $\mathbf{k}$ a $\mathbf{k}$.

Temos, portanto, um espaço de busca de tamanho aproximado de $25^{*} 10^{27}$. Tal valor impossibilita a idéia de utilizar um algoritmo de força bruta para encontrar a estratégia a ser utilizada contra o jogador. A importância de se utilizar um jogo contendo tal espaço de busca se baseia na idéia de que, se for possível demonstrar que o algoritmo de aprendizado apresenta bom desempenho neste caso, é esperado que para problemas similares, mas com espaços de busca menor o algoritmo pode apresentar um desempenho ainda melhor. Algoritmos evolutivos são normalmente utilizados para trabalhar em grandes espaços de busca, onde algoritmos de força bruta não são uma alternativa viável. 
Jogos da complexidade de Baldur's Gate buscam ainda que entre esta grande quantidade de possibilidades, não exista uma estratégia A que não possa ser vencida por uma outra estratégia B, pois a existência de uma estratégia invencível, se descoberta, acaba com qualquer desafio que o jogo possa apresentar. É importante atentar também ao fato de que embora o espaço de busca seja do tamanho apresentado, não é o objetivo encontrar a melhor estratégia possível. O objetivo é encontrar uma estratégia que ofereça ao jogador desafio suficiente para que o jogo se torne interessante. Em outras palavras, não é objetivo do algoritmo, dentro do ambiente de jogo, encontrar um ótimo global para o problema.

Por fim, outra característica do problema apresentado, é de que o mesmo é um problema dinâmico, e, portanto, necessita de constante adaptação do algoritmo de aprendizado utilizado. O que justifica tal afirmação é o fato do jogador ter a liberdade de modificar a estratégia que utiliza a qualquer hora do jogo, e assim o fazer para vencer os desafios apresentados. Desta forma, as estratégias a serem encontradas dentro deste espaço de busca variam a cada momento do jogo. 


\section{OS EXPERIMENTOS}

Com a finalidade de responder as questões apresentadas na seção 1.4 (Objetivo Geral), é necessário verificar se o AE implementado durante o trabalho apresenta os quatro requisitos para um aprendizado on-line utilizável na prática: Rápido, Efetivo, Robusto e Eficiente. O AE proposto foi projetado de maneira a cumprir pelo menos três dos requisitos:

- Rápido: o AE proposto é rápido, pois funciona entre as batalhas exigindo apenas uma pequena quantidade de operações lógicas e aritméticas. Desta forma a próxima batalha é rapidamente carregada, sem que o processamento feito pelo computador seja notado pelo usuário, ou seja, o jogador não precisa ficar esperando uma grande quantidade de processamento para continuar jogando.

- Robusto: o AE proposto é robusto, pois nenhuma regra é excluída em momento algum, ou seja, todas as regras podem voltar a ser utilizadas em algum momento do jogo devido ao operador evolutivo de mutação. Desta forma, mesmo que uma regra seja prejudicada devido ao estilo de um jogador, a mesma não é excluída permanentemente. Ela poderá reaparecer devido à mutação e caso o jogador mude de estratégia, ela poderá ter um efeito positivo na pontuação, sendo incorporada na população de scripts.

- Efetivo: P. Spronck afirma que AEs são incapazes de garantir que as soluções geradas sejam pelo menos tão desafiadoras quanto soluções projetadas manualmente [13]. No entanto, também afirma que a técnica $D S$ desenvolvida sempre produz soluções pelo menos tão desafiadoras quanto aquelas projetadas manualmente, por utilizar regras baseadas em domínio de conhecimento (as regras pertencentes à base de regras são projetadas manualmente) [13]. O AE proposto neste trabalho possui como função 
realizar a seleção de regras também baseadas em domínio de conhecimento. Sendo assim, utilizando a mesma argumentação de P. Spronck, o AE proposto também cumpre o requisito de ser efetivo.

Foi necessário então realizar experimentos para verificar se o quarto requisito (eficiência) é cumprido pelo algoritmo. Para esta finalidade, foram repetidos os testes realizados durante o trabalho de P. Spronck para verificar a eficiência da técnica DS. Tais experimentos se baseiam em projetar scripts manualmente que simulem um jogador humano. Após o script ser projetado, o jogo é realizado, sendo que um conjunto de personagens (personagens do jogador) é controlado pelo script pré-concebido, e os outros (personagens do computador) controlados pelos scripts gerados pelo AE proposto.

As estratégias projetadas para simular um jogador humano são:

- Ofensivo: os personagens do jogador possuem como prioridade diminuir a vida de seus oponentes na maior velocidade possível: guerreiros sempre atacam o inimigo mais próximo, enquanto os magos usam suas magias de dano mais fortes.

- Deteriorante: os guerreiros iniciam a batalha utilizando poções contra paralisia; após isso atacam o inimigo mais próximo. Os magos utilizam todas as suas magias para debilitar os oponentes (como, por exemplo, magia de paralisação) durante os primeiros turnos.

- Amaldiçoante: guerreiros sempre atacam o inimigo mais próximo; os magos utilizam magias de invocação, redução de atributos, e magias de controle.

- Defensivo: guerreiros começam bebendo poções que reduzam dano do elemento fogo (diminuindo dano de algumas magias); após isso, atacam o inimigo mais próximo. Os magos usam todas suas magias defensivas e magias de invocação. 
As técnicas propostas até o momento não apresentam variações durante a batalha. Isto geralmente não ocorre com um oponente humano, portanto outras três técnicas compostas foram criadas:

- Técnica aleatória: a cada batalha, uma das quatro táticas apresentadas anteriormente é selecionada de maneira aleatória.

- Técnica aleatória para cada personagem: para cada batalha, cada um dos personagens utiliza aleatoriamente um script relativo a uma das primeiras quatro técnicas apresentadas anteriormente. A escolha de um script para um personagem não depende da escolha dos scripts para os outros personagens do grupo.

- Mudança de estratégias: O grupo começa utilizando uma das quatro primeiras técnicas aleatoriamente. Enquanto a técnica utilizada pelo grupo é vitoriosa, ela é mantida; quando a técnica é derrotada, outra é selecionada.

Para avaliar a eficiência das técnicas desenvolvidas pelo $\mathrm{AE}$ em relação às técnicas apresentadas para simular o jogador, a cada batalha foi calculada a aptidão média dos grupos durante as últimas 10 batalhas. Quando este valor for maior para o grupo controlado pelo computador, é dito que a estratégia do computador dominou a estratégia do usuário. A partir da estatística apresentada, serão verificados dois valores:

1. Ponto de equilíbrio médio: número da primeira batalha após a qual o grupo controlado pelo computador domina o grupo do usuário por pelo menos 10 batalhas consecutivas.

2. Ponto de equilíbrio absoluto: número da primeira batalha após a qual um número consecutivo de batalhas em que o grupo do computador vence o grupo 
do usuário nunca é seguido por um número maior de batalhas consecutivas em que o grupo do jogador vence o grupo do computador.

Os valores destes pontos de equilíbrio são avaliados para revelar a eficiência do algoritmo, sendo que quanto menores os valores encontrados mais eficientes são os algoritmos. As simulações realizadas são mostradas abaixo. Quando o oponente enfrentado estiver indicado como "jogador humano", isto significa que haverá uma disputa entre as estratégias geradas pelo algoritmo de adaptação contra cada uma das estratégias elaboradas manualmente que simulam um jogador humano (apresentadas acima nesta mesma seção).

\section{DS X Jogador Humano}

\section{AE X Jogador Humano}

\section{AE X DS}

Os resultados coletados durante estas simulações foram avaliados com o objetivo de verificar a eficiência do AE implementado. Estes resultados também possibilitam a comparação entre os dois algoritmos de aprendizado on-line: o $D S$ proposto por P. Spronck e o AE proposto neste trabalho. 


\section{RESULTADOS OBTIDOS}

Depois de implementados os algoritmos de aprendizado, foram realizados experimentos para verificar se os mesmos apresentam capacidade de adaptação. Para isso, os personagens adaptados pela técnica DS disputaram duas mil partidas contra personagens com a estratégia ofensiva, explicada no capítulo anterior, que possui o objetivo de simular um jogador humano e foi implementada codificando o conhecimento de um especialista. Em cada partida, as pontuações das duas equipes são obtidas através da Equação 1 e podem ser comparadas. A equipe com maior pontuação é considerada a vencedora na partida em questão. Os dados coletados são exibidos no gráfico da Figura 14.

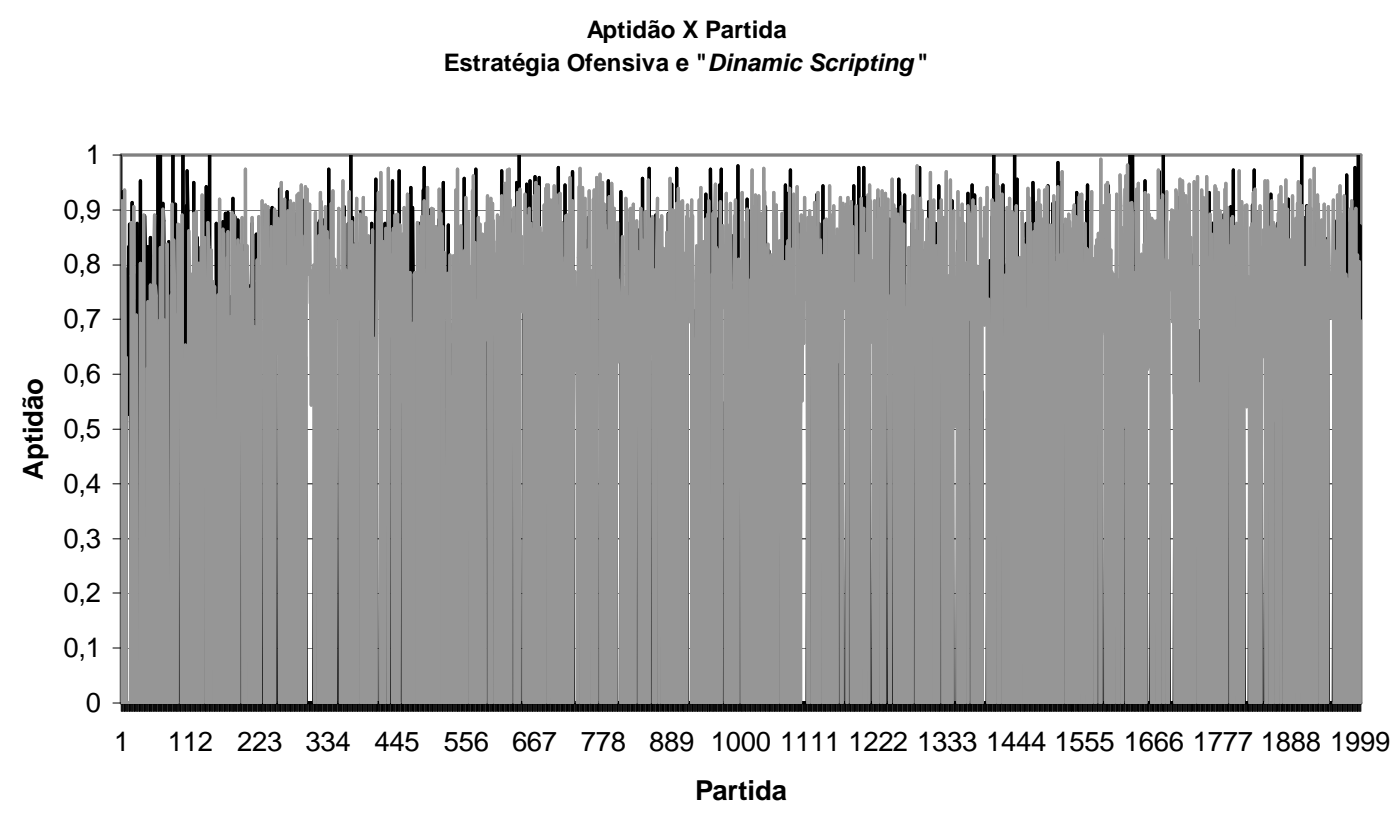

- Estratégia Ofensiva —DS

Figura 14 - DS Disputando Contra a Estratégia Ofensiva, Gráfico de Aptidão por Partida

As curvas da Figura 14 não são facilmente interpretadas devido à instabilidade dos valores de pontuação encontrados de uma partida para a outra. Tal ruído é comumente encontrado em jogos eletrônicos, justificando inclusive o critério de robustez que um algoritmo de aprendizado on-line deve satisfazer. Faz-se então necessário verificar se este 
gráfico apresenta alguma tendência agrupando-se os valores. Médias móveis permitem visualizar esta tendência, caso ela exista [63]. Os resultados foram novamente representados em um gráfico, utilizando média móvel com largura 10, ou seja, cada ponto representado no novo gráfico da Figura 15 possui um valor "pontuação média" que representa a média aritmética do fitness das 10 partidas anteriores. A equação da média móvel utilizada está representada pela Equação 6 abaixo:

$$
p_{i}=\frac{\sum_{k=i-9}^{i} f(k)}{10}, i \geq 10
$$

Equação 6

Sendo:

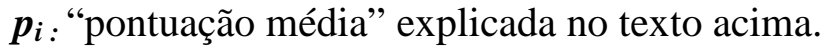

$f(k)$ : A pontuação da equipe sendo avaliada, explicada pela

Os pontos de equilíbrio médio e absoluto encontrados no experimento representado pela Figura 15 foram 54 e 92 respectivamente. O mesmo experimento foi realizado para se verificar a capacidade de adaptação do AE. Desta vez, para a exibição dos dados, foi utilizada a média móvel feita com a pontuação obtida pela função de avaliação da equipe utilizada no AE, representada pela Equação 5 Os dados coletados desta forma estão representados no gráfico da Figura 16, e apresentaram pontos de equilíbrio médio e absoluto de 41 e 43 respectivamente. 


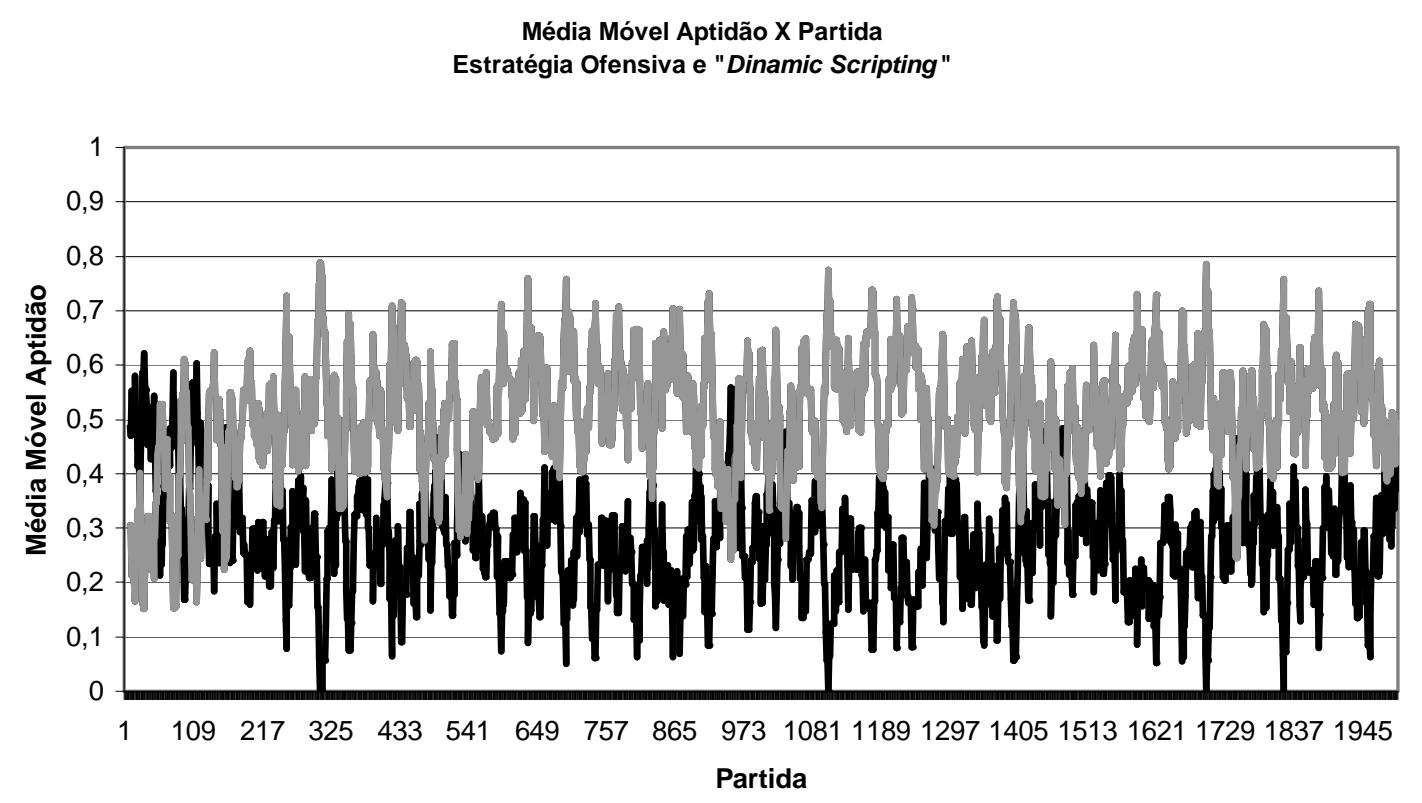

—10 por. méd. móv. (Estratégia Ofensiva) — 10 por. méd. móv. (DS)

Figura 15 - DS Disputando Contra a Estratégia Ofensiva, Gráfico de Média Móvel Aptidão por Partida

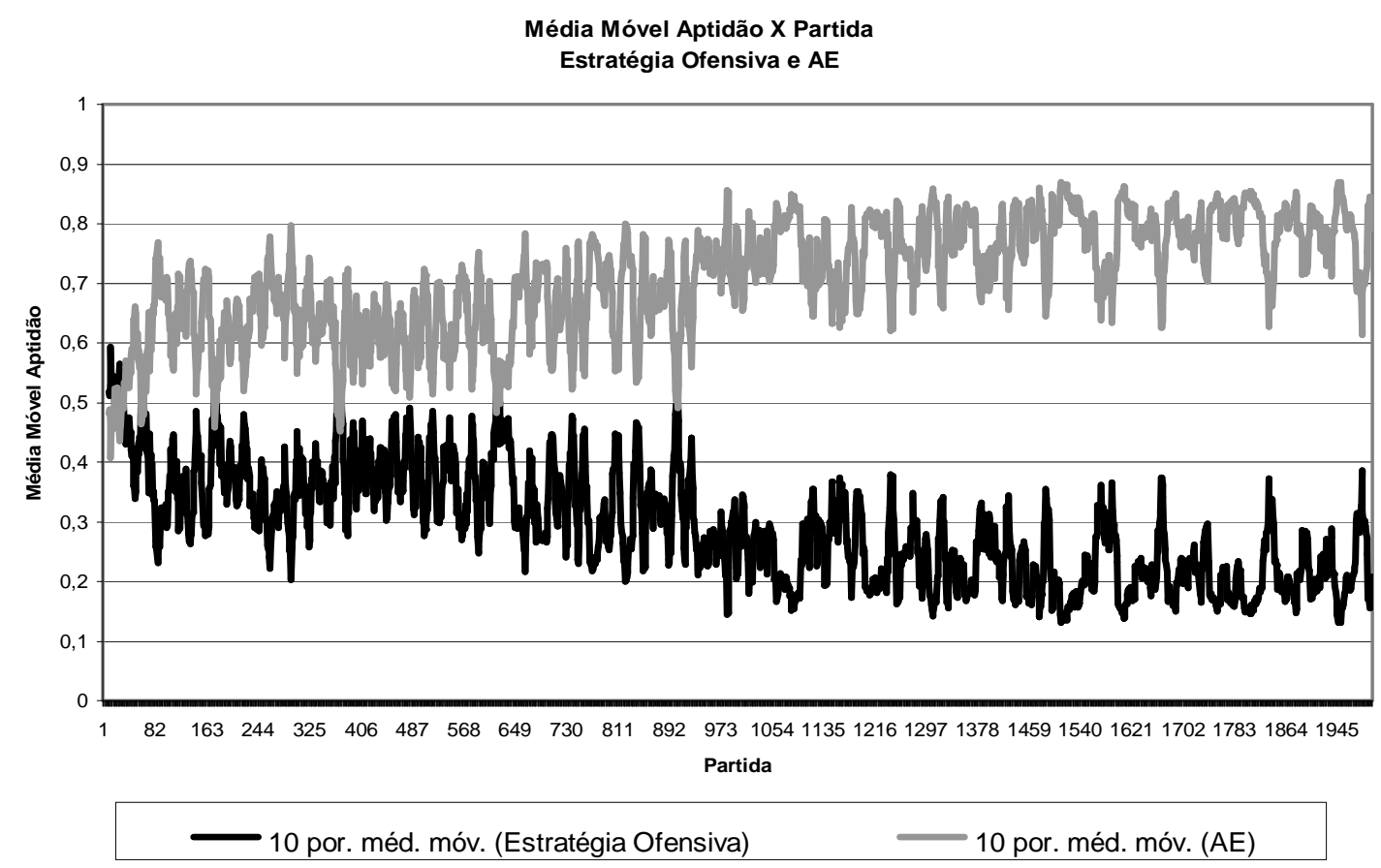

Figura 16 - AE Disputando Contra a Estratégia Ofensiva, Gráfico de Média Móvel Aptidão por Partida 
A Figura 15 e a Figura 16 permitem verificar que os algoritmos implementados apresentam capacidade de adaptação, fornecendo ao computador a capacidade de gerar estratégias que vençam a estratégia sendo enfrentada. É possível observar também que ambos os algoritmos necessitaram de um pequeno número de partidas para superar a estratégia pré-elaborada, sendo isso uma evidência de que os algoritmos satisfazem o critério de eficiência.

Para cada uma das estratégias pré-elaboradas explicadas no capítulo anterior, foram realizados 21 testes como os descritos acima contra cada algoritmo de aprendizado implementado, e para cada uma das estratégias compostas (técnica aleatória, aleatória para cada personagem, e mudança de estratégia) foram realizados 11 testes. O número de testes realizados foi assim escolhido para reproduzir os testes realizados pelo criador da técnica DS no artigo [13]. Os resultados baseados nos pontos de equilíbrio médio e absoluto podem ser visualizados na Tabela XI e Tabela XII. É importante observar que, de acordo com as definições dos pontos de equilíbrio, quanto menores os valores encontrados, mais eficiente é o algoritmo.

A Tabela XII representa os resultados obtidos neste trabalho. A tabela referente aos mesmos experimentos realizados pelo criador da técnica DS pode ser encontrada na Tabela com Resultados da Técnica DS, Extraída do Artigo [13]

Tabela XVII do Apêndice I. Nos dois trabalhos, a estratégia "Mudança de Estratégia" foi a indicada pela mediana como a mais difícil de ser vencida. É possível verificar também que as estratégias pré-elaboradas possuem algumas diferenças: 
Tabela XI - Resultados obtidos confrontando os scripts desenvolvidos pela técnica DS com as estratégias pré-elaboradas da primeira coluna.

\begin{tabular}{|l|c|c|c|c|c|c|c|c|}
\hline \multicolumn{10}{|c|}{ Dynamic Scripting } \\
\hline & \multicolumn{7}{|c|}{ Ponto de Equilíbrio Médio } & \multicolumn{3}{c|}{ Ponto de Equilíbrio Absoluto } \\
\hline Estratégias & Menor & Maior & Média & Mediana & Menor & Maior & Média & Mediana \\
\hline Ofensiva & 12 & 1129 & 88 & 38 & 15 & 1919 & 158 & 47 \\
\hline Deteriorante & 11 & 36 & 20 & 18 & 1 & 832 & 112 & 28 \\
\hline Amaldiçoante & 11 & 51 & 26 & 22 & 6 & 115 & 39 & 31 \\
\hline Defensiva & 11 & 48 & 18 & 12 & 1 & 80 & 21 & 12 \\
\hline Aleatória & 11 & 214 & 70 & 53 & 70 & --- & $406^{15}$ & 174 \\
\hline $\begin{array}{l}\text { Personagens } \\
\text { Aleatórios }\end{array}$ & 11 & 35 & 17 & 16 & 1 & 70 & 21 & 18 \\
\hline $\begin{array}{l}\text { Mudança de } \\
\text { Estratégia }\end{array}$ & 11 & 102 & 60 & 56 & 62 & 1938 & 507 & 254 \\
\hline
\end{tabular}

1. A estratégia "Deteriorante" apresentou maior dificuldade a ser vencida neste trabalho do que em [13].

2. A estratégia Defensiva apresentou maior facilidade a ser vencida neste trabalho do que em [13].

3. A estratégia "Aleatória" apresentou neste trabalho um caso em que a técnica DS não conseguiu obter um ponto de equilíbrio absoluto (tal verificação encontra-se explicada mais adiante). $\mathrm{O}$ valor da média neste caso foi calculado apenas para os 10 testes em que um ponto de equilíbrio absoluto foi encontrado.

Tais diferenças são naturais dado que o ambiente construído neste trabalho não é exatamente igual, embora tenha sido montado de maneira a se assemelhar ao ambiente de

\footnotetext{
${ }^{15}$ Neste caso, o valor da média foi calculado utilizando apenas os 10 testes em que um ponto de equilíbrio absoluto foi encontrado.
} 
[13]. Além disso, as estratégias foram montadas por especialistas diferentes, embora sigam a mesma idéia nos dois trabalhos.

O importante é verificar a eficiência da técnica DS nos dois trabalhos, independente das diferenças do ambiente e das estratégias enfrentadas. Com relação a isso, observações feitas em [13] com relação a tabela do Apêndice 1 são também válidas para a Tabela XI deste trabalho. Tais observações são realizadas mais adiante, após a Tabela XII, acrescidas de novas observações feitas comparando-se as duas técnicas.

Tabela XII - Resultados obtidos confrontando os scripts desenvolvidos pelo AE com as estratégias préelaboradas da primeira coluna.

\begin{tabular}{|l|c|c|c|c|c|c|c|c|}
\hline \multicolumn{8}{|c|}{ Algoritmo Evolutivo } \\
\hline & \multicolumn{9}{|c|}{ Ponto de Equilíbrio Médio } & \multicolumn{3}{c|}{ Ponto de Equilíbrio Absoluto } \\
\hline Estratégias & Menor & Maior & Média & Mediana & Menor & Maior & Média & Mediana \\
\hline Ofensiva & 11 & 167 & 61 & 40 & 1 & 1331 & 192 & 107 \\
\hline Deteriorante & 11 & 170 & 30 & 17 & 1 & 328 & 81 & 28 \\
\hline Amaldiçoante & 11 & 354 & 54 & 22 & 1 & 1326 & 174 & 38 \\
\hline Defensiva & 11 & 124 & 18 & 11 & 1 & 137 & 13 & 4 \\
\hline Aleatória & 11 & 364 & 62 & 28 & 6 & 1798 & 505 & 102 \\
\hline $\begin{array}{l}\text { Personagens } \\
\text { Aleatórios }\end{array}$ & 11 & 20 & 14 & 13 & 1 & 340 & 67 & 25 \\
\hline $\begin{array}{l}\text { Mudança de } \\
\text { Estratégia }\end{array}$ & 11 & 184 & 50 & 28 & 4 & 1996 & 776 & 506 \\
\hline
\end{tabular}

Analisando as duas tabelas, é possível observar que:

1. Em todos os experimentos, e para os dois pontos de equilíbrio, a média sempre possui valor maior que a mediana. Isso se explica pelo fato de serem raras as ocorrências de pontos de equilíbrio com valores altos.

2. Ambos os algoritmos mostraram médias e medianas factíveis para os pontos de equilíbrio médio, isto é, para que a adaptação ocorra, é necessário que o jogador jogue uma quantidade de partidas aceitável (levando em consideração que cada 
partida leva geralmente menos de um minuto no jogo implementado). Tal constatação indica que os algoritmos são eficientes.

3. Comparando as duas tabelas, é difícil afirmar qual é o melhor algoritmo, sendo que em alguns testes, a técnica DS obteve melhores resultados, e em outros a utilização do AE teve melhor desempenho.

4. Ao enfrentar a estratégia "Aleatória", A técnica DS não conseguiu obter um turning point absoluto em um dos experimentos. A ocorrência de tal acontecimento é dada ao fato de que em algumas partidas, devido ao fator sorte, a técnica DS pode aumentar o peso de regras não adequadas, e até mesmo excluir regras necessárias para obter uma estratégia vencedora. Tal limitação do algoritmo já havia sido constatada pelos desenvolvedores da técnica. O fato de permitir que o peso mínimo para uma regra seja zero (Equação 3) resulta em uma grave desvantagem, pois com o passar do tempo, a técnica perde a capacidade de adaptar suas estratégias.

Para chegar a uma melhor comparação entre os algoritmos, a próxima etapa dos testes foi realizada, confrontando no jogo as duas técnicas. Ou seja, enquanto um grupo de personagens é evoluído pelo AE, o grupo oponente foi adaptado pela técnica DS. Os pontos de equilíbrio obtidos pelo AE podem ser verificados na Tabela XIII. Enquanto os obtidos pela técnica DS se encontram Tabela XIV. Para obtenção destes pontos de equilíbrio foram realizados 21 testes, cada um composto por duas mil partidas. Os pontos de equilíbrio encontrados em todos os testes realizados podem ser encontrados na Tabela XVIII do Anexo I. 
Tabela XIII - Pontos de Equilíbrio obtidos pelo AE ao confrontar a técnica DS

\begin{tabular}{|c|c|c|c|c|c|c|c|}
\hline \multicolumn{8}{|c|}{ Algoritmo Evolutivo } \\
\hline \multicolumn{7}{|c|}{ Ponto de Equilíbrio Médio } & \multicolumn{3}{c|}{ Ponto de Equilíbrio Absoluto } \\
\hline Low & High & Avg & Med & Low & High & Avg & Med \\
\hline 11 & 393 & 49 & 12 & 2 & --- & 598 & 391 \\
\hline
\end{tabular}

Tabela XIV - Pontos de Equilíbrio obtidos pela técnica DS ao confrontar o AE

\begin{tabular}{|c|c|c|c|c|c|c|c|}
\hline \multicolumn{10}{|c|}{ Dynamic Scripting } \\
\hline \multicolumn{7}{|c|}{ Ponto de Equilíbrio Médio } & \multicolumn{4}{c|}{ Ponto de Equilíbrio Absoluto } \\
\hline Low & High & Avg & Med & Low & High & Avg & Med \\
\hline 11 & 240 & 55 & 38 & 76 & --- & 1172 & 1997 \\
\hline
\end{tabular}

Olhando os pontos de equilíbrio obtidos a partir deste experimento, é possível observar que:

1. Tanto o AE quanto a técnica DS encontraram casos em que não foi possível obter um ponto de equilíbrio absoluto. Dos 21 testes realizados, o AE não conseguiu obter um ponto de equilíbrio absoluto em 2 testes. Já a técnica DS não foi capaz de obter este ponto de equilíbrio em 5 testes. O valor da média foi calculado utilizando apenas os testes em que um ponto de equilíbrio absoluto foi encontrado.

2. A mediana do ponto de equilíbrio absoluto obtida pela técnica DS foi de 1997. Este valor é muito alto considerando o número de partidas realizadas em cada teste (2000), o que é um indicador de que o AE dominou a técnica DS na maioria das partidas.

3. As médias e as medianas apresentaram melhores resultados para as estratégias desenvolvidas pelo AE.

A fim de verificar as constatações 2 e 3 realizadas acima, foram verificados os comportamentos dos testes realizados. Foi constatado nos testes que o grupo adaptado pela 
técnica DS perde a capacidade de adaptação após algumas batalhas. Tal constatação é coerente com a observação realizada no experimento anterior, no qual a técnica DS não consegue encontrar um ponto de equilíbrio absoluto ao confrontar a estratégia "Aleatória". A Figura 17 mostra um dos testes realizados onde é possível visualizar a perda da capacidade de adaptação da técnica DS com o passar do tempo.

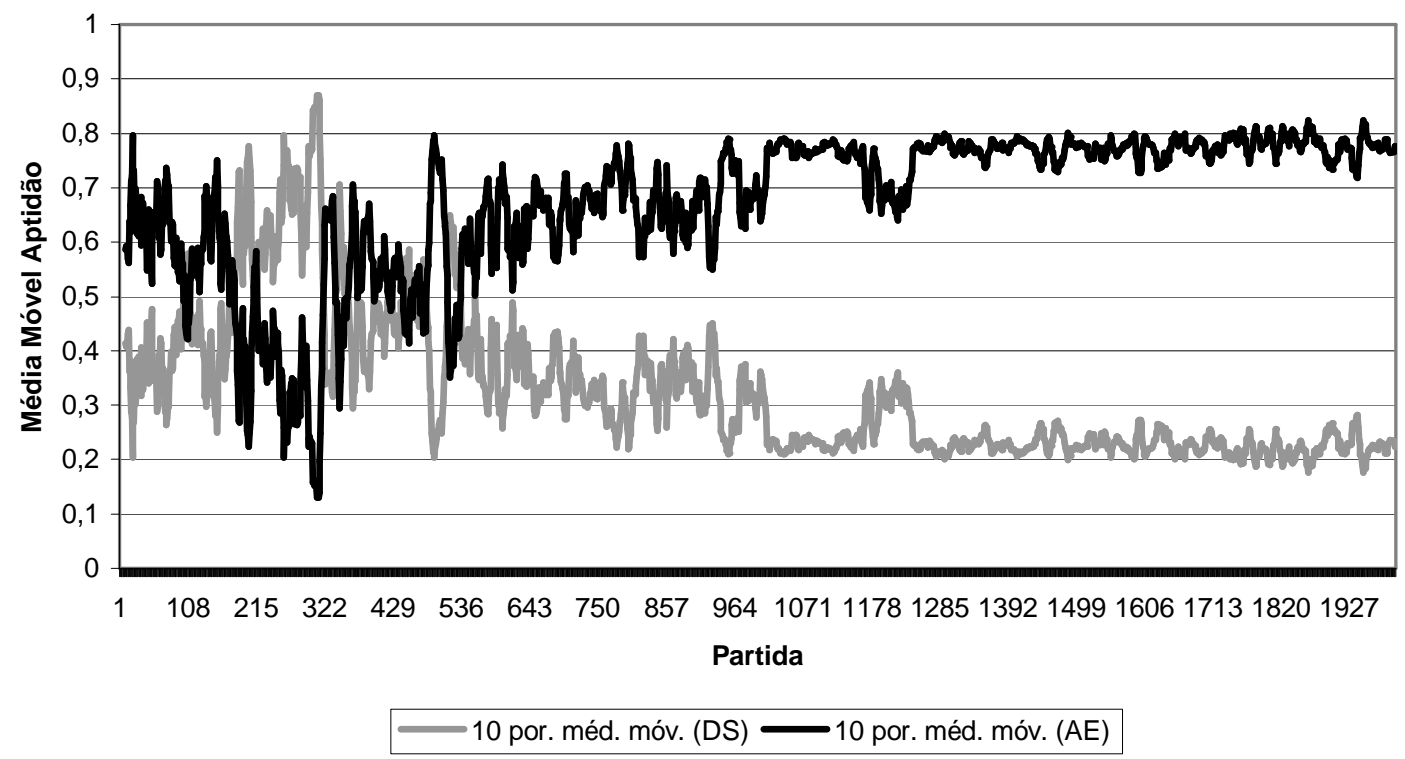

Figura 17 - AE Disputando Contra a Técnica DS, Gráfico de Média Móvel Aptidão por Partida

Para colher dados capazes de confirmar a superioridade do AE sobre a técnica DS ao longo de um jogo composto por 2000 partidas, foi utilizado um método que utiliza como critério o erro máximo de estimação com um nível de confiança de 95\% [64] [65]. O método utilizado é explicado pela Figura 18. 


\section{Repita}

2 Realize um jogo composto por 2000 partidas;

3 Calcule a frequiência das partidas vencidas pelo grupo adaptado pelo Algoritmo Evolutivo;

Até que (Número de Jogos > 200) ou (erro máximo $<0.05 *$ (Média dos valores calculados no passo 3)).

\section{Figura 18 - Método Adotado para a Coleta dos Dados}

No passo 2, o jogo é realizado como no experimento relatado anteriormente, realizando 2000 partidas. No passo 3 o valor calculado da amostra (freqüência das partidas vencidas pelo grupo adaptado pelo Algoritmo Evolutivo durante o jogo i) é chamado de $\mathrm{x}_{\mathrm{i}}$ e dado pela razão abaixo:

$$
\mathrm{x}_{\mathrm{i}}=\frac{V A E}{N P}
$$

Sendo:

$\boldsymbol{V A E} \quad$ Número de vitórias obtidas pelo grupo cuja estratégia é evoluída pelo AE

NP Número total de partidas realizadas, (2000 neste caso).

No critério de parada, o erro máximo (e) é calculado a partir dos valores amostrados até o momento [64] [65]. A fórmula para cálculo deste erro é dada pela

Equação 7:

$$
e=\sqrt{\frac{s^{2}}{n}}
$$


Sendo:
e erro máximo
$\mathbf{s}^{2} \quad$ variância amostral
n número de jogos realizados (amostras)

A variância amostral ( $\mathbf{s}^{2}$ ) é estimada através da Equação 8 abaixo.

$$
s^{2}=\frac{1}{n-1} \sum_{i=1}^{n}\left(x_{i}-\bar{x}\right)^{2}
$$

Equação 8

Sendo:
$\mathbf{x}_{\mathbf{i}} \quad$ Valor da amostra
$\bar{x} \quad$ Média das amostras
n Nmero de jogos realizados (amostras)

Os resultados obtidos encontram-se no gráfico da Figura 19 abaixo, onde as colunas indicam as frequiências obtidas de vitórias do AE e da técnica DS, e o intervalo indicado sobre as colunas representa o intervalo de possíveis valores para as frequiências esperadas, considerando o erro máximo encontrado. Tais resultados permitem concluir, com um nível de confiança de $95 \%$, que em um jogo composto por 2000 partidas, as estratégias geradas pelo $\mathrm{AE}$ vencem as estratégias geradas pela técnica DS na maioria das vezes. A afirmação é possível de ser realizada, pois é visível no gráfico que o pior caso do $\mathrm{AE}$ (freqüência encontrada de vitórias do AE menos o erro máximo) é melhor que o melhor caso da técnica DS (freqüência encontrada de vitórias da técnica DS mais erro máximo). Tal resultado é esperado, dada a constatação de que a técnica DS perde a capacidade de adaptar sua estratégia após um determinado número de partidas, sendo que 2000 partidas são suficientes para se verificar tal acontecimento, como visto no experimento anterior. Os casos de empate não foram exibidos no gráfico pois se mostraram desprezíveis (casos de empates e erro máximo de aproximadamente $0 \%$ ). Os valores obtidos pelo experimento se encontram na Tabela XIX 
do Anexo II.

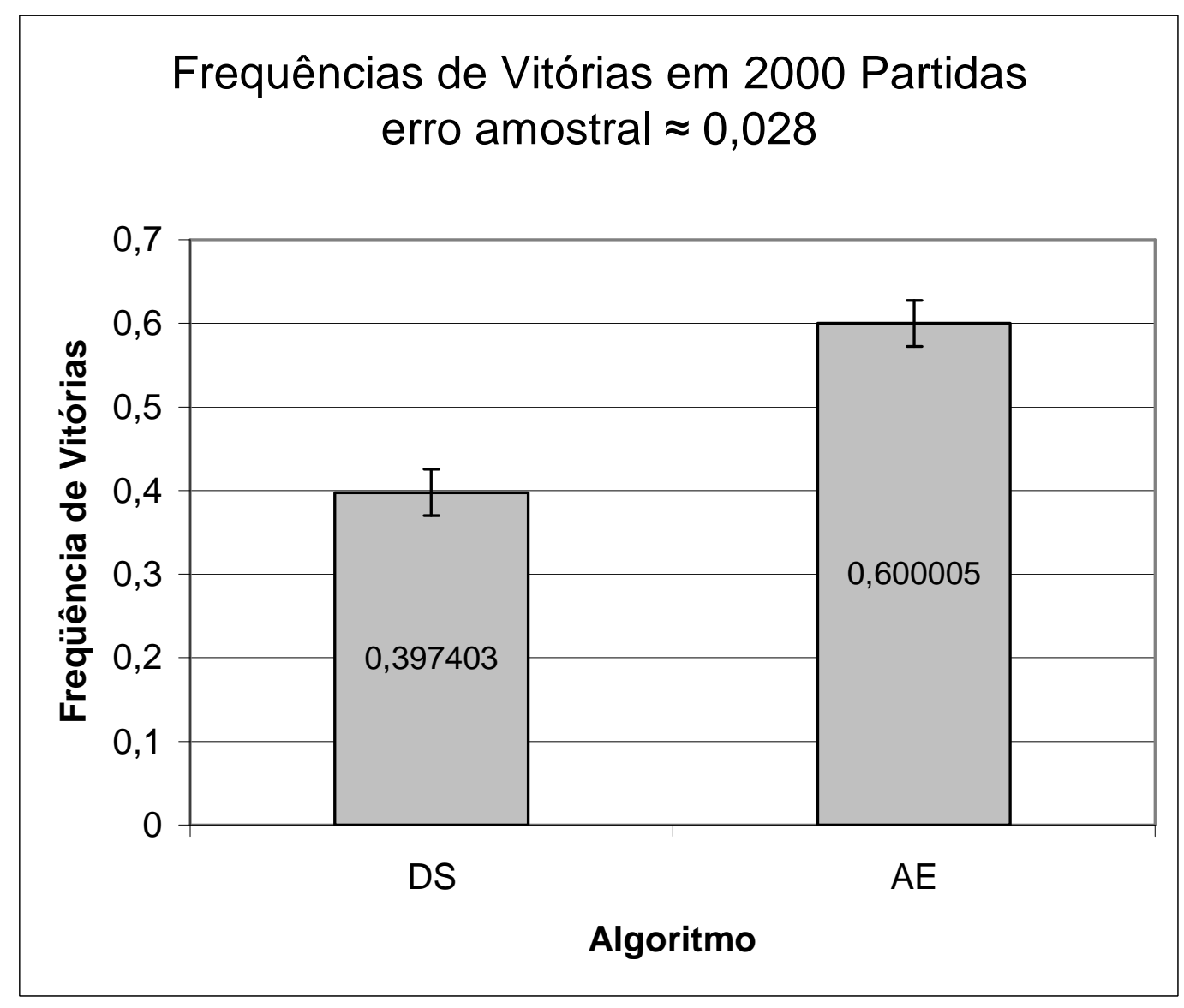

Figura 19 - Freqüência de Vitórias das Técnicas AE e DS em 2000 Partidas

Os resultados explicados até o momento são suficientes para apontar os Algoritmos Evolutivos como uma melhor opção (com relação à técnica DS) a ser utilizada em jogos nos quais a adaptação deve ocorrer continuamente. Em jogos em que ocorrem poucas partidas, as duas técnicas seriam aceitáveis, pois a técnica DS só perde sua capacidade de adaptação após um número de partidas suficiente para reduzir os pesos de suas regras a zero (a quantidade de partidas varia de acordo com fatores como o espaço de busca e a quantidade de aleatoriedade do jogo). No entanto, isso não permite comparar as duas técnicas com relação ao critério de eficiência, pois o mesmo diz respeito a um número pequeno de partidas para que o aprendizado ocorra. Para comparar este critério, o último experimento foi repetido, mas desta 
vez o número de partidas por jogos foi diminuído, realizando testes para 300, 200, 100 e 50 partidas por jogo. Os resultados do teste podem ser visualizados na Figura 20 abaixo.
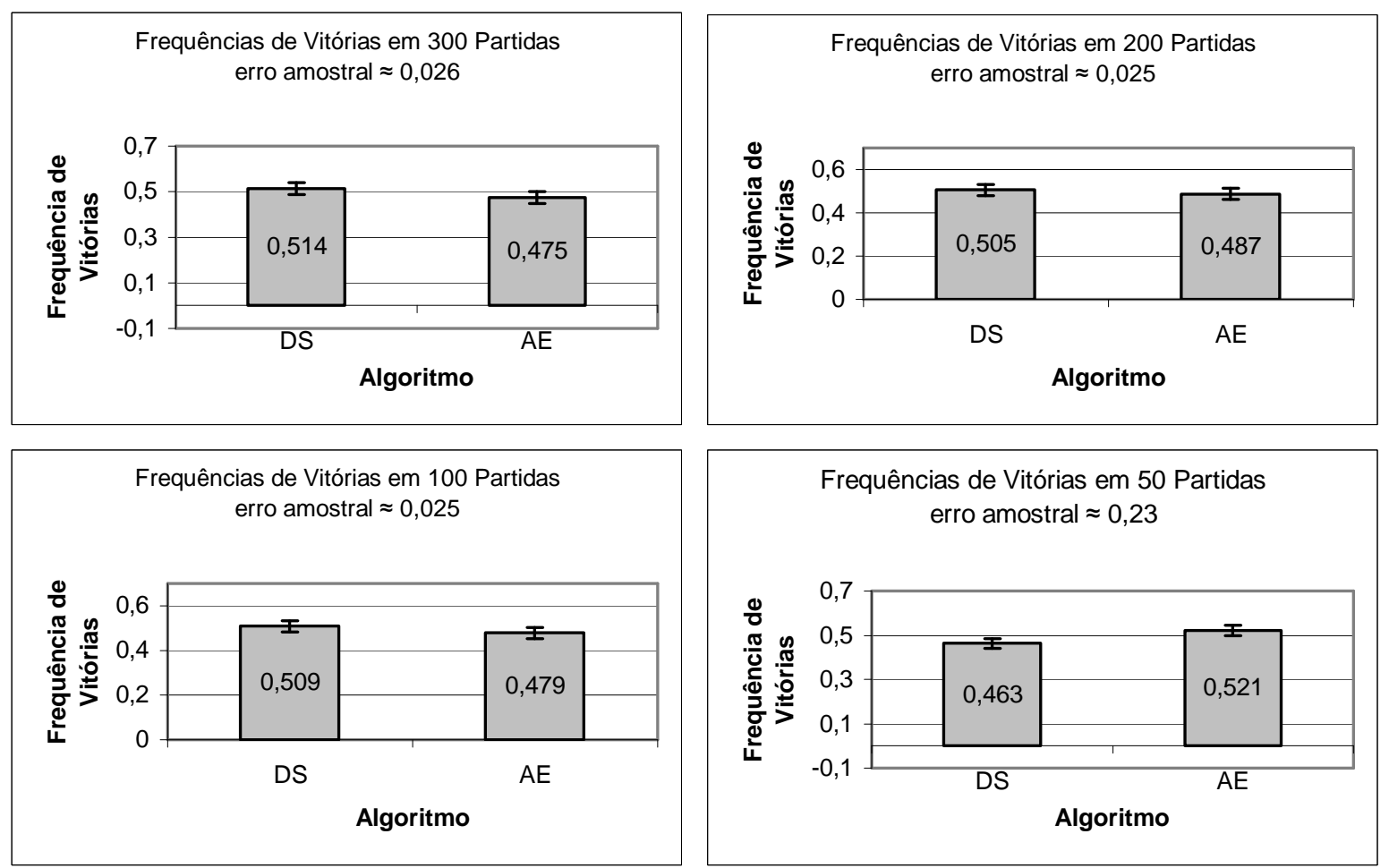

Figura 20 - Comparação das freqüências de vitórias entre o AE implementado e técnica DS. Resultados coletados utilizando 300, 200, 100 e 50 partidas por jogo.

Mais uma vez os casos de empate não foram mostrados no gráfico acima pois se mostraram desprezíveis (os valores obtidos podem ser encontrados na Tabela XIX do Anexo II). Observando os dados resultantes dos experimentos, é possível verificar que as frequiências de vitórias obtidas para o AE e para a técnica DS foram similares. Só é possível concluir que a eficiência de uma técnica de aprendizado 'A' é superior à eficiência da outra técnica de aprendizado 'B', se o pior caso de 'A' for superior ao melhor caso de 'B'. Ao dizer pior ou melhor caso, é considerado o erro máximo, assim como feito no experimento com 2000 
partidas por jogo. De outra maneira, podemos afirmar a superioridade da técnica 'A' com relação à técnica 'B' caso a inequação abaixo seja satisfeita [64] [65]:

$$
\mathrm{FVA}-\mathrm{ea}>\mathrm{FVB}+\mathrm{eb}
$$

Sendo:

FVA Frequiência de Vitórias do Grupo cujos scripts foram adaptados pela técnica 'A'

FVB Freqüência de Vitórias do Grupo cujos scripts foram adaptados pela técnica 'B'

ea erro máximo da Percentagem de Vitórias do Grupo cujos scripts foram adaptados pela técnica 'A'

eb erro máximo da Percentagem de Vitórias do Grupo cujos scripts foram adaptado pela técnica 'B'

Em nenhum dos resultados apresentados pela Figura 20 pode ser constatada superioridade na eficiência da técnica DS sobre o $\mathrm{AE}$, já que, embora alguns experimentos apontem a técnica DS como vencedora (experimentos com 300, 200 e 100 partidas por jogo), ao considerar o erro máximo encontrado tal superioridade não pode ser admitida, pois nenhum dos experimentos torna verdadeira a inequação apresentada acima. As inequações resultantes destas verificações podem ser visualizadas na Tabela XV abaixo. É valido avisar que a soma das freqüências de uma linha da tabela não é exatamente um, pois existem os casos de empate (que possuem valores a partir da quarta casa decimal) e também devido a arredondamentos realizados pelo computador. 
Tabela XV - Verificação da superioridade da técnica DS, na inequação apresentada, FVA e FVB representam a percentagem de vitórias da técnica DS e AE respectivamente. Os termos ea e eb representam, nesta ordem, os erros amostrais de FVA e FVB.

\begin{tabular}{|c|c|c|}
\hline \multicolumn{3}{|c|}{ Verificação da Superioridade da técnica Dynamic Scripting } \\
\hline Partidas por jogo & FVA - ea $>$ FVB + eb & Validade da Inequação \\
\hline 300 & $0,488716>0,500972$ & Falsa \\
\hline 200 & $0,480273>0,513059$ & Falsa \\
\hline 100 & $0,483811>0,504557$ & Falsa \\
\hline 50 & $0,440483>0,544976$ & Falsa \\
\hline
\end{tabular}

De maneira análoga, ao se comparar a superioridade do AE sobre a técnica DS, é possível verificar a superioridade do AE no último experimento realizado (50 partidas por jogo), pois os dados coletados tornam válida a inequação verificada. Tal afirmação pode ser confirmada verificando a Tabela XVI abaixo.

Tabela XVI - Verificação da superioridade do AE implementado, na inequação apresentada, FVA e FVB representam a percentagem de vitórias das técnicas AE e DS respectivamente. Os termos ea e eb representam, nesta ordem, os erros amostrais de FVA e FVB.

\begin{tabular}{|c|c|c|}
\hline \multicolumn{3}{|c|}{ Verificação da Superioridade da técnica Algorimo Evolutivo } \\
\hline Partidas por jogo & FVA - ea $>$ FVB + eb & Validade da Inequação \\
\hline 300 & $0,450444>0,540118$ & Falsa \\
\hline 200 & $0,462367>0,530737$ & Falsa \\
\hline 100 & $0,453843>0,534589$ & Falsa \\
\hline 50 & $0,49882>0,486525$ & Verdadeira \\
\hline
\end{tabular}

É possível concluir, com base nos dados obtidos, que a eficiência apresentada pelo AE se mostrou melhor ou próxima a da técnica DS, que já teve sua eficiência verificada no trabalho de Spronck. Com tal verificação tornou-se evidente que Algoritmos Evolutivos podem satisfazer o critério de eficiência para um aprendizado on-line que funcione na prática. Atingido este objetivo, os experimentos foram finalizados. 


\section{CONCLUSÕES}

A proposta deste trabalho foi a de verificar a possibilidade de se construir um Algoritmo Evolutivo (AE) capaz de ser aplicado de fato no aprendizado on-line em jogos, capacidade esta apontada como impossível por alguns autores [13] [6]. Para o cumprimento de tal objetivo, inicialmente foi realizada uma revisão bibliográfica que apresentou fatos encorajadores, pois possibilitou encontrar trabalhos que diziam ter obtido aprendizado on-line eficiente utilizando Algoritmos Evolutivos e Redes Neurais Artificiais.

Para constatar que um algoritmo de aprendizado on-line funciona de fato, foi necessário verificar se o mesmo satisfaz quatro requisitos [13]: rapidez, robustez, efetividade e eficiência. Destes requisitos, os dois últimos foram apontados por autores como Spronck e Ponsen como sendo inviáveis de se obter quando utilizando um AE. O AE proposto foi projetado de maneira a cumprir pelo menos três dos requisitos: rapidez, robustez e efetividade. Para mostrar a presença destes critérios, foi suficiente realizar uma comparação com base na estrutura do algoritmo, comparando-a com outra técnica de aprendizado chamada DS que satisfaz os quatro requisitos. Para verificar se o AE proposto satisfaz também o critério de eficiência, foi necessário:

1. Produzir um jogo como ambiente de testes baseado em um famoso e complexo jogo comercial. Assim como uma linguagem de scripting capaz de controlar o comportamento dos personagens que compõem o mesmo. Para a produção deste jogo, foi procurado recriar o ambiente de testes produzido pelos criadores da técnica DS, cujos detalhes explicados no artigo [13] exigiram grande atenção para estarem presentes também no jogo produzido neste trabalho. O jogo implementado se mostrou adequado ao trabalho, pois encontra-se muito similar ao descrito no artigo em questão, podendo apresentar pequenas diferenças devido a abstração de 
alguns detalhes na descrição do ambiente criado pelos autores da técnica DS. Como exemplo, as magias implementadas no trabalho de Spronck não foram explicitamente citadas, no entanto, várias tornaram-se evidentes durante a descrição de seu trabalho. Devido a grande atenção exigida e também à complexidade do jogo, esta etapa exigiu muito tempo para ser realizada, e só foi concluída em tempo admissível devido ao reaproveitamento de código, extraído de outro trabalho realizado anteriormente [45].

2. Propor e codificar um AE, realizando testes sobre a função de avaliação utilizada, e otimizando suas funções evolutivas. Inicialmente a função de avaliação utilizada seria igual a função de avaliação do time utilizada pela técnica DS. No entanto, os testes realizados durante esta etapa mostraram a necessidade de se modificar esta avaliação para o funcionamento junto ao AE implementado. A taxa de mutação e o tamanho da população do AE foram definidos empiricamente, realizando alguns testes nesta etapa do projeto.

3. Implementar a técnica DS e realizar testes para verificar a capacidade de adaptação da mesma. Para isso foi necessário um estudo cuidadoso da técnica a fim de não cometer enganos em sua implementação. Os testes realizados permitiram verificar a correta implementação desta, assim como mostrar sua capacidade de adaptação.

4. Elaborar estratégias de jogo, com o objetivo de simular um jogador humano para permitir a realização de grandes quantidades de testes com as técnicas de aprendizado. Estas estratégias foram extraídas do trabalho de Spronck, e procuraram ser reproduzidas neste trabalho.

5. Adicionar ao código do jogo um sistema automático de coleta de dados sobre o desempenho dos algoritmos. Para isso foi necessário acrescentar ao jogo um 
módulo responsável por gerar saídas em formato texto contendo resultados referentes aos jogos e partidas realizados. Esta etapa exigiu uma atenção especial e uma grande quantidade de testes a fim de verificar que os dados estavam sendo impressos corretamente.

6. Reproduzir, para os dois algoritmos de aprendizado, os testes realizados para verificar a eficiência da técnica DS no trabalho onde a mesma foi proposta, assim como realizar testes confrontando diretamente os dois algoritmos de aprendizado. Nesta etapa foi necessário um estudo detalhado sobre os testes realizados no artigo que apresenta a técnica DS [13]. Também foi necessário uma pequena modificação no código do jogo para permitir que os dois times fossem simultaneamente adaptados por algoritmos de aprendizado.

7. Avaliar os dados coletados segundo os critérios estatísticos adotados durante a etapa seis. Dificuldades foram encontradas com o rigor estatístico a ser utilizado. Foi então buscado o auxílio de um especialista da área de estatística, que se mostrou de grande ajuda para o cumprimento desta etapa.

Ao final da última etapa descrita acima, foi possível verificar que o algoritmo de aprendizado proposto neste trabalho satisfaz também o último requisito: o de eficiência. Além disso, foi também observado que o algoritmo em questão apresenta eficiência melhor ou similar a da técnica DS, cuja eficiência já havia sido comprovada no trabalho [13]. Tal constatação permite responder à pergunta chave deste trabalho: sim, é possível desenvolver um AE que satisfaça os quatro requisitos: rapidez, robustez, efetividade e eficiência.

Os testes realizados permitiram verificar uma deficiência da técnica DS: esta perde a capacidade de adaptação após um determinado tempo de funcionamento. Tal deficiência se 
deve ao fato da técnica permitir a atribuição de peso zero para regras sendo selecionadas, como mostrado na Equação 3. Uma forma para corrigir tal deficiência seria definindo um peso mínimo de valor maior que zero a ser utilizado. Desta forma, nenhuma regra seria permanentemente descartada, e, portanto, a técnica preservaria sua capacidade de adaptação. No entanto, é provável que com esta correção a eficiência da técnica diminua, pois regras que já tenham sido testadas, e tenham se mostrado inadequadas contra a estratégia utilizada, continuariam apresentando a possibilidade de serem testadas.

A obtenção de um AE como o implementado neste trabalho traz contribuições para o campo de Inteligência Artificial aplicada a jogos, no qual é reconhecido que as possíveis aplicações para AE são numerosas, embora a técnica encontre certa resistência para ser aceita pelos desenvolvedores de jogos. Tal resistência é reforçada por afirmações como as contestadas e negadas neste trabalho. Portanto, espera-se com este trabalho, que os desenvolvedores de jogos tornem-se mais receptivos às técnicas evolutivas de IA.

Uma aplicação em potencial de AEs seria em jogos como MMORGPs (explicados no capitulo 3), que estão em destaque atualmente. Este tipo de jogo permite que uma grande quantidade de usuários jogue simultaneamente. Um AE para o aprendizado on-line destes jogos possuiria uma grande vantagem: trabalhar com grandes populações. Além disso, a avaliação de seus indivíduos poderia ocorrer de forma paralela, sendo que cada jogador funcionaria como uma função de avaliação para os oponentes que os enfrentassem.

O nível de complexidade do jogo produzido foi escolhido de maneira a ser alto quando comparado a outros jogos mais simples (espaço de busca de tamanho $25^{*} 10^{27}$ aproximadamente) [22]. Desta forma, ao se constatar que o AE apresentou bom desempenho neste jogo, é esperado que em jogos similares, mas com soluções contidas em um espaço de busca menor do que o deste projeto o AE apresente um desempenho ainda melhor. 
Em suma, foram obtidos neste trabalho:

1. Uma revisão sobre técnicas utilizadas na Inteligência Artificial dos jogos atuais.

2. Um jogo ${ }^{16}$ com alta complexidade que serve como ambiente de testes para técnicas de aprendizado on-line.

3. Um AE capaz de produzir estratégias inteligentes adaptadas às estratégias utilizadas pelo usuário em tempo de jogo. Além disto, foi verificado que este algoritmo funciona na prática, pois satisfaz quatro requisitos: rapidez, efetividade, robustez e eficiência.

4. Resultados experimentais que: (1) mostram que o AE implementado é mais eficiente ou apresenta eficiência similar a da técnica DS desenvolvida por Spronck; (2) apontam deficiências da técnica DS e sugestões de melhorias para a mesma; e (3) negam afirmações que dão suporte à resistência encontrada para a aceitação de AEs por desenvolvedores de jogos.

Ao se concluir este trabalho, várias alternativas para sua continuação foram encontradas, dentre as quais podem ser citadas:

1. Implementar a correção proposta para a técnica DS e realizar outros experimentos para verificar se o mesmo continua satisfazendo o critério de eficiência.

2. Melhorar o jogo implementado para que este proponha maior entretenimento aos jogadores.

3. Comparar outros algoritmos de aprendizado com os utilizados neste trabalho.

4. Tentar encontrar AEs que se mostrem ainda mais eficientes que o deste trabalho

${ }^{16}$ Site do jogo ZantArena. Disponível em: <http://quadros.no-ip.org/zantarena〉. Acesso em: 02 fev. 2008. 


\section{REFERÊNCIAS}

[1] NPD GROUP. Essential Facts About the Computer and Video Game Industry. Elaborado por Enterteinment Software Association. Disponível em: <http://www.theesa.com/files/2005EssentialFacts.pdf>. Acesso em: 22 fev. 2007.

[2] BITTENCOURT, João Ricardo; OSÓRIO, Fernando S. Motores de Jogos para Criação de Jogos Digitais - Gráficos, Áudio, Interface, Rede, Inteligência Artificial e Física. In: ESCOLA REGIONAL DE INFORMÁTICA DE MINAS GERAIS, 5, 2006, Belo Horizonte, Mg. Anais da V ERI-MG SBC. Belo Horizonte, MG: Eri-mg, 2006. V. 1, p. 1 - 36.

[3] SWEETSER, Penelope. Current AI in Games: A review. Brisbane: University Of Queensland, 2002. 18 p.

[4] Lionhead Studios. Black \& White 2. Disponível em: 〈http://www.lionhead.com/bw2/〉. Acesso em: 22 fev. 2007.

[5] Eletronic Arts. The Sims. Disponível em: <http://thesims.ea.com/>. Acesso em: 22 fev. 2007.

[6] PONSEN, Marc. Improving Adaptive Game AI with Evolutionary Learning. 2004. 46 f. Dissertação (Mestrado) - Faculty Of Media \& Knowledge Engineering, Delft University Of Technology, Delft, 2004.

[7] PRECHELT, L.. Are scripting languages any good? A validation of Perl, Python, Rexx, and $\mathrm{Tcl}$ against $\mathrm{C}, \mathrm{C}++$, and Java. In: ZELKOWITZ, Marvin. Advances in Computers: Highly Dependable Software. 58. ed. New York: Academic Press, 2003. p. 207-271.

[8] ZADEH, Lofti A. A Fuzzy-Algorithmic Approach to the Definition of Complex or Imprecise Concepts. In: Intl. J. Man-Machine Studies 3. 1976. p. 249-291. Vol.8.

[9] NARDI, Renzo De. Flocking of UAVs. Software Model and Limited Vision Simulations. 2004. 104 f. Tesi Di Laurea (Doutorado) - University Of Padua, Padua, 2004.

[10] MARTINEZ, Dominique. Competitive Learning in Decision Trees. In: CONFERENCE ON COMPUTING ANTICIPATORY SYSTEMS, 1., 1997, Liège. Proceedings of the AIP Conference. Liège: University Of Liège, 1997. p. 660 - 670.

[11] HAYKIN, Simon. Redes Neurais: Princípios e Prática. 2. Ed. Porto Alegre: Bookman, 2001.898 p.

[12] YANNAKAKIS, Georgios N. AI in Computer Games: Generating Interesting Interactive Opponents by the use of Evolutionary Computation. 2005. $257 \mathrm{f}$. Tese (Doutorado) - University Of Edinburgh, Edinburgh, 2005. 
[13] SPRONCK, P.; SHPRINKHUIZEN-KUYPER, I.; POSTMA, E. Online Adaptation of Game Opponent AI in Theory and Practice. In: INTERNATIONAL CONFERENCE ON INTELLIGENT GAMES AND SIMULATION, 4, 2003, Londres. Proceedings of the 4th International Conference on Intelligent Games and Simulation. Wolverhampton: University Of Wolverhampton, 2004. p. 45 - 53.

[14] KAELBLING, Leslie P.; Littman, Michael L. Reinforcement Learning: A Survey. In: Journal of Artificial Intelligence Research 4: JAIR, 1996. p. 237-285.

[15] RABIN, Steve. AI Game Programming Wisdom. Charles River Media, 2002. 672 p. ISBN 1584500778.

[16] DELOURA, Mark A. Game Programming Gems. 1. ed. Charles River Media, 2000. $614 \mathrm{p}$.

[17] MANSLOW, John. Learning and Adaptation. In: STEVE RABIN. AI game Programming Wisdom. Washington: Charles River Media, 2002. p. 557-566. CD-ROM.

[18] OSTERGAARD, E. H.; LUND, H. H.. Co-Evolving Complex Robot Behavior. In: INTERNATIONAL CONFERENCE ON EVOLVABLE SYSTEMS, 5, 2003, Trondheim. Proceedings of The 5th International Conference on Evolvable Systems. Trondheim: Springer Verlag, 2003. p. 308 - 319.

[19] ZITZLER, Eckart; THIELE, Lothar. An Evolutionary Algorithm for Multiobjective Optimization: The Strength Pareto Approach. Zurich: Swiss Federal Institute Of Technology, 1998. 43 p.

[20] SIMÕES, Eduardo do Valle; DIMOND, Keith R. Embedding a Distributed Evolutionary System into a Population of Autonomous Mobile Robots. In: IEEE INTERNATIONAL CONFERENCE ON SYSTEMS, MAN AND CYBERNETICS, 2001, Tucson, Az. Proceedings of The IEEE International Conference on Systems, Man and Cybernetics. Tucson, AZ: IEEE, 2001. p. 1069 - 1074.

[21] LUCAS, S. Cellz: A Simple Dynamic Game for Testing Evolutionary Algorithms. In: IEEE CONGRESS ON EVOLUTIONARY COMPUTATION, 2004, San Diego, CA. Proceedings of The IEEE Congress on Evolutionary Computation. San Diego, CA: IEEE, 2004. p. 1007 - 1014.

[22] FAIRCLOUGH, Chris et al. Research Directions for AI in Computer Games. In: IRISH CONFERENCE ON AI AND COGNITIVE SCIENCE, 12., 2001, Kildare. Proceedings of the 12 Irish Conference on AI and Cognitive Science. Kildare: AICS, 2001. p. 1 - 12.

[23] PERUCIA, Alexandre Souza et al. Desenvolvimento de Jogos Eletrônicos: Teoria e Prática. São Paulo, SP: Novatec, 2005. 302 p. 
[24] DINÍZIO, Clailson Soares; SIMÕES, Marco Antonio Costa. Inteligência Artificial em Jogos de Tiro em Primeira Pessoa. Revista Eletrônica de Iniciação Científica, SBC Sociedade Brasileira de Computação, v. 3, n. 1, p.1-12, mar. 2003. Ano 3. ISSN 1519-8219. Disponível em: <http://www.sbc.org.br/reic/edicoes/2003e1/>. Acesso em: 22 fev. 2007.

[25] MALLOUK, Willian; CLUA, Esteban. An Object Oriented Approach for Hierarchical State Machines. In: SBGAMES, 5., 2006, Recife, PE. Anais da SBGames 2006. Recife, PE: SBGames, $2006 . \quad$ p. 112 - $7 . \quad$ Disponível $\quad$ em: <http://cin.ufpe.br/ sbgames/proceedings/papers.htm>. Acesso em: 22 fev. 2007.

[26] LAU, Manfred; KUFFNER, James. Behavior Planning for Character Animation. In: EUROGRAPHICS SYMPOSIUM ON COMPUTER ANIMATION, 4., 2005, Los-Angeles, CA. Proceedings of the Symposium On Computer Animation. [Los-angeles]: ACM Siggraph, 2005. p. 1 - 10.

[27] MCNAUGHTON, M. et al. Code Generation for AI Scripting in Computer Role-Playing Games. In: AAAI-04, 1., 2004, San Jose, CA. Proceedings of the Challenges in Game AI Workshop. San Jose, CA: AAAI, 2004. p. 129 - 133.

[28] CARBONARO, Mike et al. Interactive Story Writing in the Classroom: Using Computer Games. In: DIGRA, 2., 2005, Vancouver. Proceedings of DiGRA. Vancouver: Digra, 2005. p. $323-338$.

[29] PRENDINGER, Helmut; ISHIZUKA, Mitsuru. SCREAM: SCRipting Emotion-based Agent Minds. In: AAMAS-02, 1., 2002, Bologna, BO. Proceedings First International Joint Conference on Autonomous Agents and Multi-Agent Systems. Bologna, BO: AAMAS, 2002. p. 1 - 2.

[30] TATAI, Victor Kazuo. Técnicas de Sistemas Inteligentes Aplicadas. 2003. 129 f. Dissertação (Mestrado) - Universidade Estadual de Campinas, Campinas, SP, 2003.

[31] COLLINS, Alex Edwin. Evaluating the Performance of AI Techniques in the Domain of Computer Games. Sheffield: University Of Sheffield, 2001. 65 p.

[32] DEMASI, Pedro; CRUZ, Adriano Joaquim de Oliveira. Aprendizado de Regras Nebulosas em Tempo Real para Jogos Eletrônicos. In: WORKSHOP DE JOGOS E ENTRETENIMENTO DIGITAL, 2., 2003, Salvador, BA. Proceedings on Computer Games and Digital Enterteinment. Salvador, BA: WJogos, 2003. p. 1 - 9.

[33] RIEDER, Rafael; BRANCHER, Jacques Dúlio. Aplicação da Lógica Fuzzy a Jogos Didáticos de Computador - A Experiência do Mercadão GL. In: CONGRESSO ÍBERO AMERICANO DE INFORMÁTICA EDUCATIVA, 7., 2004, Monterrey, NL. Anais do VII Congresso Ibero Americano de Informática Educativa. Monterrey, NL: VII Congresso Ibero Americano de Informática Educativa, 2004. p. 1 - 10. 
[34] DEMASI, Pedro; CRUZ, Adriano Joaquim de Oliveira. Modelagem Fuzzy para um Jogo de Naves Espaciais. In: WORKSHOP BRASILEIRO DE JOGOS E ENTRETENIMENTO DIGITAL, 1., 2002, Fortaleza, CE. Anais WJogos 2002. Fortaleza, CE: WJogos, 2002. p. 1 4.

[35] AOYAGI, Masaru; NAMATAME, Akira. Massive individual based simulation: forming and reforming of flocking behaviors. In: ASIA PACIFIC SYMPOSIUM ON INTELLIGENT AND EVOLUTIONARY SYSTEMS, 8., 2004, Cairns, Queensland. Proceedings of the 8th Asia Pacific Symposium on Intelligent and Evolutionary Systems. Cairns, Queensland: Monash University, 2004. p. 1 - 5.

[36] BAYAZIT, O. Burchan; LIEN, Jyh-ming; AMATO, Nancy M.. Roadmap-Based Flocking for Complex Environments. In: PACIFIC CONFERENCE ON COMPUTER GRAPHICS AND APPLICATIONS, 10., 2002, Beijing. Proceedings of the Pacific Conference on Computer Graphics and Applications. Beijing: IEEE Computer Society, 2002. p. $104-115$.

[37] OLFATI-SABER, Reza. Flocking for Multi-Agent Dynamic Systems: Algorithms and Theory. Hanover, NH: IEEE Control Systems Society, 2004. 37 p. ISSN: 0018-9286.

[38] QUINLAN, Ross J. Improved Use of Continuous Attributes in C4.5. In: Journal of Artificial Intelligence Research 4: JAIR, 1996. p. 77-90.

[39] KONUR, Savas; FERREIN, Alexander; LAKEMEYER, Gerhard. Learning Decision Trees for Action Selection. In: EUROPEAN CONFERENCE ON ARTIFICAL INTELLIGENCE, 16., 2004, Valencia. Proceedings of Workshop on Agents in Dynamic and Real-Time Environments. Valencia: ECAI, 2004. p. 1 - 7.

[40] BOYAN, Justin. Modular Neural Networks for Learning Context-Dependent Game Strategies. Chicago: Cambridge University, 1991.

[41] LUBBERTS, Alex; MIIKKULAINEN, Risto. Co-Evolving a Go-Playing Neural Network. In: GENETIC AND EVOLUTIONARY COMPUTATION CONFERENCE, 6. 2001, San Francisco, Ca. Proceedings In Coevolution: Turning Adaptive Algorithms upon Themselves. San Francisco, CA: GECCO, 2001.p. 1 - 6.

[42] STANLEY, Kenneth O.; BRYANT, Bobby D.; MIIKKULAINEN, Risto. Evolving Neural Network Agents in the NERO Video Game. In: SYMPOSIUM ON COMPUTATIONAL INTELLIGENCE AND GAMES, 2005, Piscataway, NJ. Proceedings of the IEEE 2005 Symposium on Computational Intelligence and Games. Piscataway, NJ: IEEE, 2005. p. 182 - 189.

[43] YAO, Xin; DARWEN, Paul. Genetic Algorithms and Evolutionary Games. In: BARNETT, Willian et al. Commerce, Complexity and Evolution. Cambridge: Cambridge University Press, 2000. p. 325-347. 
[44] KOJIMA, Takuya; UEDA, Kazuhiro; NAGANO, Saburo. An Evolutionary Algorithm Extended by Ecological Analogy and its Application to the Game of Go. In: INTERNATIONAL JOINT CONFERENCE ON ARTIFICIAL INTELLIGENCE, 15., 1997, Nagoya. Proceedings of the Fifteenth International Joint Conference on Artificial Intelligence. Nagoya: Ijcai, 1997. p. 1 - 6.

[45] CROCOMO, M. K.; MIAZAKI, M.; SIMÕES, E. V. Algoritmos evolucionários no desenvolvimento de jogos adaptativos, In: Simpósio Brasileiro de Jogos Para Computador e Entretenimento Digital - WJogos ; Workshop Brasileiro de Jogos e Entretenimento Digital, 4, Anais do WJOGOS 2005, São Paulo, SP : Zuffo, M. R. et al, pp. 342 - 347, 2005.

[46] DARWIN, Charles. The Origin of Species by Means of Natural Selection. 6. ed. London: Reading, 1859. 458 p.

[47] WHITLEY, D. A genetic algorithm tutorial. Fort Collins: Colorado State University, 1993. $10 \mathrm{p}$.

[48] KOZA, J. R. Genetic Programming: a paradigm for genetically breeding populations of computer programs to solve problems. Stanford: Sandford University, 1990. $118 \mathrm{p}$.

[49] TOMASSINI, Marco. Evolutionary Algorithms. In: TOWARDS Evolvable Hardware; The Evolutionary Engineering Approach Berlin: Springer-Verlag, 1996. p. 19-47.

[50] HARVEY, Inman. Species adaptation genetics algorithms: A Basis for a Continuing SAGA. In: EUROPEAN CONFERENCE ON ARTIFICIAL LIFE: TOWARD A PRACTICE OF AUTONOMOUS SYSTEMS, 1, 1992, Paris. Proceedings of the First European Conference on Artificial Life: Toward a Practice of Autonomous Systems. Cambridge, MA: Mit Press/Bradford Books, 1992. p. 346 - 354.

[51] TOMASSINI, Marco. A Survey of Genetic Algorithms. In: WORLD Scientific: Annual Reviews of Computational Physics: World Scientific, 1995. p. 87-118.

[52] BRAMLETTE, Mark F. Initialization, mutation and selection methods in genetic algorithms for function optimization. In: INTERNATIONAL CONFERENCE ON GENETIC ALGORITHMS, 4, 1991, San Mateo, CA. Proceedings of the Fourth International Conference on Genetic Algorithms. San Mateo, CA: ICGA, 1991. p. 100 - 107.

[53] MITCHELL, Melanie; FORREST, Stephanie. Genetic Algorithms and Artificial Life. In: ARTIFICIAL Life 3. ed. Massachusetts: Mit Press, 1994. p. 267-289. Vol.1.

[54] WATSON, R. A.; FICICI, S. G.; POLLACK, J. B. Embodied Evolution: Distributing an Evolutionary Algorithm in a Population of Robots. In: ROBOTICS and Autonomous Systems Southampton: ECS, 2002. p. 1-18. Vol. 39. 
[55] SIMÕES, Eduardo do Valle. Development of an embedded evolutionary controller to enable collision-free navigation of a population of autonomous mobile robots. 2000. 289 f. Tese (Doutorado) - Electronic Engineering, University Of Kent, Canterbury, 2000.

[56] SIMÕES, Eduardo do Valle; DIMOND, Keith R.. An evolutionary controller for autonomous Multi-Robot Systems. In: SYSTEMS, MAN AND CYBERNETICS, 1999, Tokyo. Proceedings of the IEEE International Conference on Systems, Man and Cybernetics. Tokyo: IEEE, 1999. p. 596 - 601.

[57] SIMÕES, Eduardo do Valle; BARONE, Dante Augusto Couto. Predation: an Approach to Improving the Evolution of Real Robots with a Distributed Evolutionary Controller. In: INTERNATIONAL CONFERENCE ON ROBOT AUTOMATION, 2002, New York. Proceedings of International Conference on Robot Automation. New York: IEEE Press, 2002. p. $664-669$.

[58] CROCOMO, Marcio Kassouf; SIMÕES, Eduardo do Valle; DELBEM, Alexandre Cláudio Botazzo. Otimização Automática de Parâmetros de Sistemas Evolucionários de Acordo com a Aplicação. In: ENCONTRO DE ROBÓTICA INTELIGENTE, 2., 2004, Salvador, BA. Anais do $\mathbf{1 0}^{\mathbf{}}$ Congresso da Sociedade Brasileira De Computação. Salvador, BA: SBC, 2004. p. 1 - 10.

[59] DIKUMUD Disponível em: <http://www.dikumud.com/>. Acesso em: 22 fev. 2007.

[60] COX, Alan. AberMUD. Disponível em: <http://ftp.linux.org.uk/pub/linux/alan/Software/Games/AberMUD5/>. Acesso em: 22 fev. 2007.

[61] ARMAGEDDON MUD Disponível em: 〈http://www.armageddon.org/>. Acesso em: 22 fev. 2007.

[62] Hübner, J. F., Bordini, R. H., and Vieira, R. Introdução ao Desenvolvimento de sistemas Multiagentes com Jason. In: XII Escola de Informática da SBC. Guarapuava UNICENTRO, 2004. p. 51-89. Vol. 2.

[63] MARTHA, A.; CENTENOM, F. R. So you have your model: what to do next. A tutorial on simulation output analysis, Proceedings of the 1998 Winter Simulation Conference Miami: Florida, 1998.

[64] FRANCISCO, W. Estatística: síntese de teoria, exercícios propostos e resolvidos, Piracicaba: Unimep, 1993. p. 219.

[65] BUSSAB, W.O., MORETTIN, P. A. Estatística Básica. 5. ed. SARAIVA, 2006. p. 540. ISBN 8502034979. 


\section{APÊNDICE I - TABELA COM RESULTADOS DA TÉCNICA DS, EXTRAÍDA DO}

\section{ARTIGO [13]}

Tabela XVII - Pontos de equilíbrio obtidos pela técnica Dynamic Scripting, extraída e traduzida de [13]

\begin{tabular}{|l|c|c|c|c|c|c|c|c|}
\hline \multicolumn{8}{|c|}{ Dynamic Scripting - Tabela extraída de [13] } \\
\hline & \multicolumn{7}{|c|}{ Ponto de Equilíbrio Médio } & \multicolumn{3}{c|}{ Ponto de Equilíbrio Absoluto } \\
\hline Estratégias & Menor & Maior & Média & Mediana & Menor & Maior & Média & Mediana \\
\hline Ofensiva & 27 & 164 & 57 & 54 & 27 & 159 & 53 & 45 \\
\hline Deteriorante & 11 & 14 & 11 & 11 & 1 & 10 & 3 & 1 \\
\hline Amaldiçoante & 13 & 1784 & 150 & 31 & 4 & 1778 & 144 & 31 \\
\hline Defensiva & 11 & 93 & 31 & 23 & 1 & 87 & 27 & 18 \\
\hline Aleatória & 13 & 256 & 56 & 29 & 5 & 251 & 50 & 26 \\
\hline $\begin{array}{l}\text { Personagens } \\
\text { Aleatórios }\end{array}$ & 11 & 263 & 53 & 30 & 1 & 249 & 47 & 33 \\
\hline $\begin{array}{l}\text { Mudança de } \\
\text { Estratégia }\end{array}$ & 11 & 160 & 61 & 50 & 3 & 152 & 55 & 48 \\
\hline
\end{tabular}


ANEXO I - Pontos de Equilíbrio Resultantes do Teste Realizado Confrontando as

Técnicas AE e DS

Tabela XVIII - Pontos de equilíbrio obtidos do confronto entre as técnicas AE e DS

\begin{tabular}{|c|c|c|c|c|}
\hline \multirow{2}{*}{\begin{tabular}{|c|} 
Jogo \\
número:
\end{tabular}} & \multicolumn{2}{|c|}{$\begin{array}{c}\text { Pontos referentes ao } \mathrm{AE} \\
\text { implementado }\end{array}$} & \multicolumn{2}{|c|}{$\begin{array}{c}\text { Pontos referentes à } \\
\text { técnica DS }\end{array}$} \\
\hline & $\begin{array}{l}\text { Ponto de } \\
\text { equilíbrio } \\
\text { Médio }\end{array}$ & $\begin{array}{l}\text { Ponto de } \\
\text { equilíbrio } \\
\text { absoluto }\end{array}$ & $\begin{array}{l}\text { Ponto de } \\
\text { equilíbrio } \\
\text { médio }\end{array}$ & $\begin{array}{l}\text { Ponto de } \\
\text { equilíbrio } \\
\text { absoluto }\end{array}$ \\
\hline 1 & 11 & 314 & 182 & --- \\
\hline 2 & 11 & 127 & 55 & 1999 \\
\hline 3 & 11 & 886 & 38 & 689 \\
\hline 4 & 11 & 27 & 65 & --- \\
\hline 5 & 120 & 1558 & 37 & 1385 \\
\hline 6 & 393 & 391 & 19 & --- \\
\hline 7 & 11 & 346 & 31 & 1992 \\
\hline 8 & 36 & 292 & 23 & 2000 \\
\hline 9 & 31 & 28 & 44 & --- \\
\hline 10 & 27 & 1328 & 16 & --- \\
\hline 11 & 11 & 14 & 240 & 1997 \\
\hline 12 & 11 & --- & 27 & 170 \\
\hline 13 & 11 & 71 & 40 & 1997 \\
\hline 14 & 25 & 27 & 11 & --- \\
\hline 15 & 12 & 917 & 48 & 324 \\
\hline 16 & 11 & 435 & 46 & 1974 \\
\hline 17 & 22 & 2 & 32 & 1999 \\
\hline 18 & 11 & --- & 91 & 89 \\
\hline 19 & 138 & 669 & 14 & 656 \\
\hline 20 & 15 & 1987 & 62 & 230 \\
\hline 21 & 103 & 1952 & 28 & 76 \\
\hline
\end{tabular}




\section{ANEXO II - Resultados Obtidos nos Últimos Experimentos}

Tabela XIX - Freqüência de vitórias e erro máximo obtido nos experimentos realizados confrontando as técnicas AE e DS em 2000, 300, 200, 100 e 50 partidas

\begin{tabular}{|c|ccc|}
\hline \multirow{2}{*}{ Partidas por jogo } & \multicolumn{3}{|c|}{ Valores com 6 casas decimais de precisão } \\
& \multicolumn{3}{|c|}{ (multiplicar por 100 para obter em \%) } \\
\cline { 2 - 4 } & Vitória DS & Empate & Vitória AE \\
\hline $\mathbf{2 0 0 0}$ & 0.397403 & 0.000218 & 0.600005 \\
erro máximo & 0.027693 & 0.000144 & 0.027680 \\
\hline $\mathbf{3 0 0}$ & 0.514417 & 0.000146 & 0.475708 \\
erro máximo & 0.025701 & 0.000121 & 0.025264 \\
\hline $\mathbf{2 0 0}$ & 0.505505 & 0.000106 & 0.487713 \\
erro máximo & 0.025232 & 0.000103 & 0.025346 \\
\hline $\mathbf{1 0 0}$ & 0.509200 & 0.000600 & 0.479200 \\
erro máximo & 0.025389 & 0.000468 & 0.025357 \\
\hline $\mathbf{5 0}$ & 0.463504 & 0.000146 & 0.521898 \\
erro máximo & 0.023021 & 0.000286 & 0.023078 \\
\hline
\end{tabular}

